\title{
بث بعنوان
}

إسهامات الرسائل العلمية للفدهة الاجتماعية في تضايا

البعد الاجتهاعي والبيئي للتنهمية المستداهة

\section{إعداد}

أ.د/ ناصر عويس عبد التواب

الأستاذ بقسم الخدمة الاجتماعية

جامعة أم القرى 


\section{أولاًامقدمة ومشكلة الدراسة:}

تحظى قضايا التتمية المستدامة في الآونة الأخيرة باهتمام متزايد ورغبة من كافة الدولة

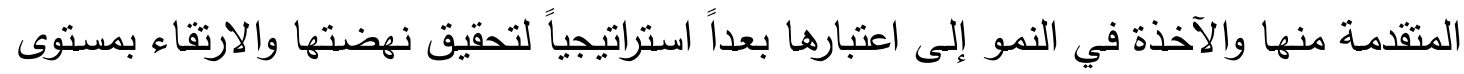
معيشة مواطنيها، وذلك من خلا إعادة صياغة رؤيتها التتموية وإنتاج فكراً معاصراً تتجاوز فيه تقليدية التتاول الحالية وذلك من خلال ربط جهود التتمية المستدامة بمعايير محددة بدونها لن يطلق على تلك الجهود بأنها تتمية مستدامة من أهمها: تغيير العقيدة الراسخة باعتبار رأس المال

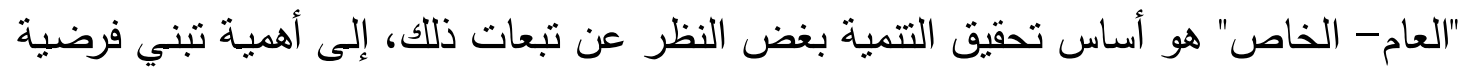

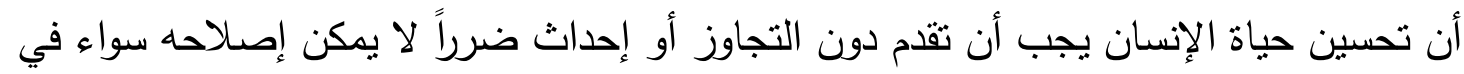
النظم الأيكولوجية أو استنفاذاً للموارد الأساسية، أو يشكل خطراً على الأجيال القاد القادمة. إن مصطلح مستذام وفق تلك المعايير أذن يشير إلى إدارة موارد ونظم المجتمع على نحو يتفق

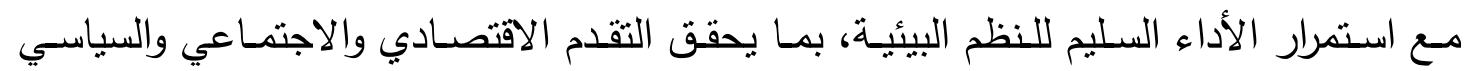
المستمر الهادف إلى رفاة المجتمع وخاصة فئات المجتمع الأكثر حرماناً. (Kevin Griffin,2014) ووفقاً لذلك المفهوم يمكن القول بأننا في حاجة إلى رؤية متكاملة نستتد عليها لتحقيق

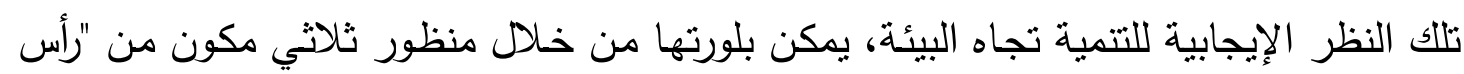
مال-بحث علمي فعال-موارد بشرية مؤهلة" يعملون في إطار متتاغم مشترك ينتقلون فيه من حالة التقليدية في التفكير والتتفيذ إلى حالة المعاصرة والابتكار والتجديد، مع الأخذ في الاعتبار أن حالة التشارك تلاك تتم في إطار عملية تدوير ، فلا قيمة لمكون بدون الآخرين. غير أن ترتيب النتاول لبدء تحقيق التتمية المستدامة المنشودة يفترض أن تتطلق من خلا روية بحثية علمية تفرز لنا دراسات وبحوث علمية ومبادرات وبرامج وتجارب ثبتت فعاليتها ونجاحها مع قضايا البعد الاجتماعي البيئي للتنمية المستدامة. وعليه يكتسب البحث العلمي أهمية خاصة ذلك إن أحسن استغلاله الاستغلال الأمثل أن

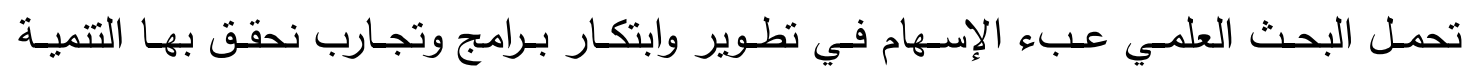

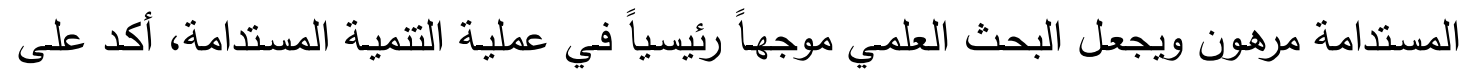

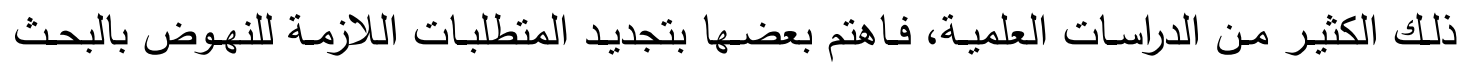

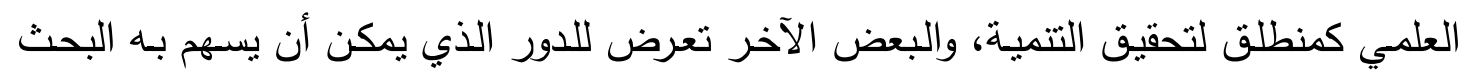
العلمي من تقدم المجتمع، والبعض تتاول للمعوقات التي تواجه البحث العلمي في الإسهام بفعالية

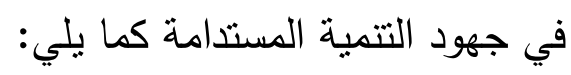


حيث أثـارت دراسـة (محمد، 999 199) والتي بعنوان "اتجاهـات البحث العلمي في كلية التربية جامعة الخرطوم"، إلى أن عدم الارتقاء بمستوى البحث العلمي يرجع إلى عدم الاعثماد عليه أو الاستفادة من نتائج بحوثه لضعف الإمكانات المادية الأمر الذي قلل من ضعف الإنفاق عليه أو أن يكون له دور في إحداث تغيير ملحوظ في عملية التتمية. أما دراسة (عبد الله، 1 . . r) والتي بعنوان "مشكلات البحوث العلمية التربوية كما يراها طلبـة الدراسـات العليـا في كليـة التربيـة جامعـة الخرطوم"، فقد أوصـت بوضـع قائمـة بأولويـات وأهداف وسياسات البحث العلمي مع ضرورة توفير الدعم المالي وتتوعه. في حين اهتم (كنسـاوي، ( + . ب) في دراسته والتي بعنوان "توجيه البحث العلمي في الدراسات العليا في الجامعات السعودية لتلبية منطلبات التمية الاقتصادية والاجتماعية بمحاولة تحديـد سـبل النهـوض بالبحث العلمي، وتوضـيح المعوقـات التي تواجـه ربط البحث العلمي بمتطلبات التتمية"، ولقد أسفرث نتائج البحث عن وجود معوقات لتتشيط حركة البحث العلمي الجامعي ترتبط بنواحي مالية وفنية وتتظيمية، كما توجد صعوبات في التعاون بين الجامعات وقطاعات المجتمع المسئولة عن البعد التتموي في مجال البحث العلمي، وأن السبيل للتغلب عليه هو تأسيس مجالس للتعاون بين الجامعات ومؤسسات تتموية متتوعة..

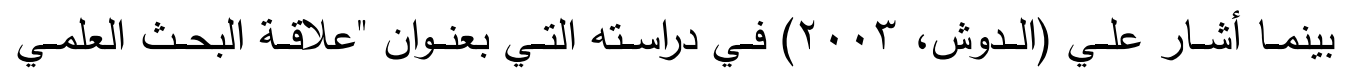
بالتتميـة"، إلـى ضـعف ارتبـاط الأبحـاث العلميـة المنجـزة بأهـداف وسياسـات خطـط التتميـة الاقتصادية والاجتماعية، وإلى غياب الخطة البحثية على مستوى الجامعة والكلية والقسم.

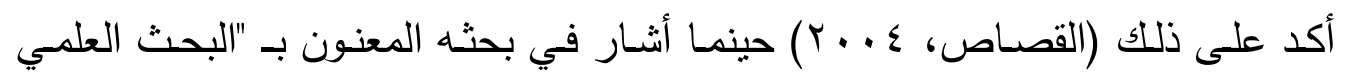
ومتطلبـات البـاحثين إلى افتقار البحث العلمي لسياسـة عامـة واضـحة، وعدم الالتـزام ببـرامج وسياسات اجثماعية محددة سلفاً".

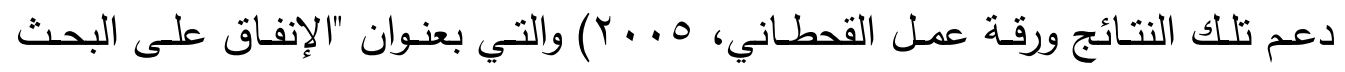
العلمي الجامعي الواقع والمـأمول" والتي أثـار فيها إلى أن من العوامل التي تنؤثر في تثشيط البحث العلمي في الجامعات هو ضآلة حجم الإنفاق على البحث العلمي. أمـا دراسـة اللحلح، 9 . . ب) والتي بعنوان "تفعيل العلاقة بين مؤسسـات البحث العلمي وقطاعات الأعمال لخدمة أهداف التتمية" فقد أثـارت إلى أن سبل التفعيل تحتاج إلى ضرورة استغلال قطاعات الأعمال لنتائج البحوث والدراسات العلمية وإلى ودعم جهود التعاون بينهما. 


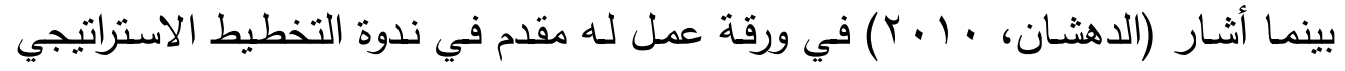
للتعليم العالي، إلى ضرورة أن تتطور العلاقة بين الجامعات كجهات بحثية علمية والمؤسسات الارتباطية التتموية في مستويات متدرجة لتصل إلى المستوى المؤدي إلى فكرة الثراكة التامة المتكاملة لإنتاج مشاريع مشتركة كبرى تشهم في تتمية المجتمع وتطوره. نخلص مما سبق إلى أن جهود أبي مجتمع يسعى إلى تحقيق التتمية المستدامة، لن لن

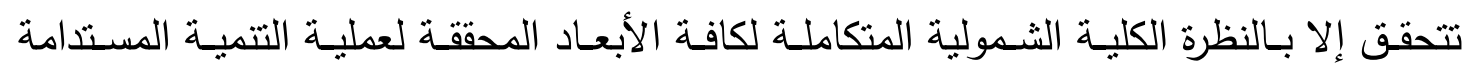
المنشودة وأن للبحث العلمي دوراً حيوياً يفرض على المسئولين والقائمين عليه تغيير فلسفتهم له له

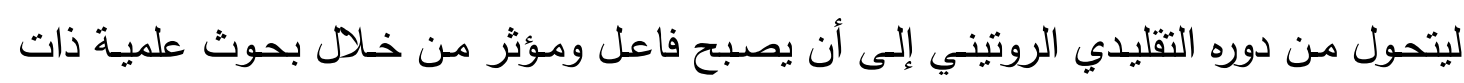
مردود مجتمعي تحدث فارقاً نهضوياً ينعكس على المواطنين بالإيجاب والمجتمع بالثقام. وهو الأمر الذي يفرض على الجامعات أن تعيد صياغة رؤيتها واستراتيجياتها العلمية لتكون جامعـات متكاملة Integrated University تقوم على إنتاج المعرفة التتمويـة وحاضينة لأفكار ومعامل وتجارب حقيقية تثارك بفاعلية في إيجاد حلول لمشاكل المجتمع وتدعم توطين التكنولوجيا المعرفية وترعى الكوادر والعقول الفكرية المبدعة. ووفقاً لذلك فإن مشاركة كافة العلوم والتخصصات العلمية في عمليات التتمية المرجوة تحتاج منا أولاً الوقوف على واقع إبسهاماتها وجهودها لتحدد بناء عليها نقطة الانطلاق المثلى فئى

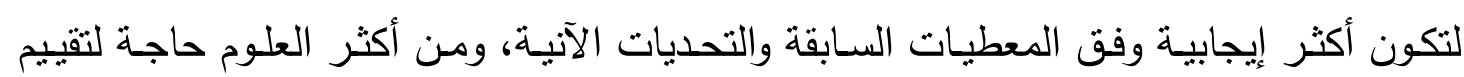

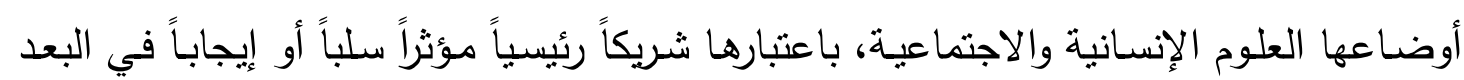

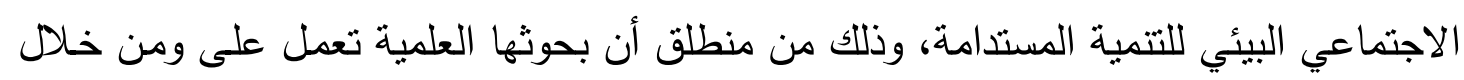

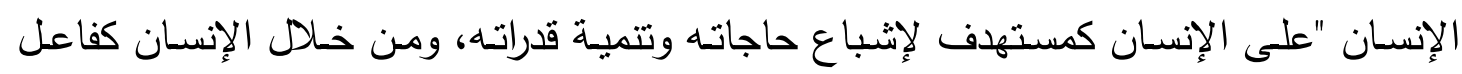
محدث للتغيير من خلا باحثيه وممارسيه". فإذا كانت الدراسات السابقة نطالب البحث العلمي بالتطوير والابتكار والإبداع فإن الأمر يزداد أهمية في العلوم الإنسانية الاجتماعية - بصفة عامة- وفي الخدمة الاجتماعية - بصفة

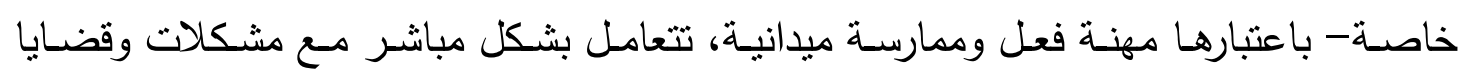

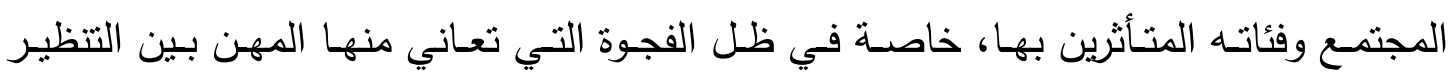

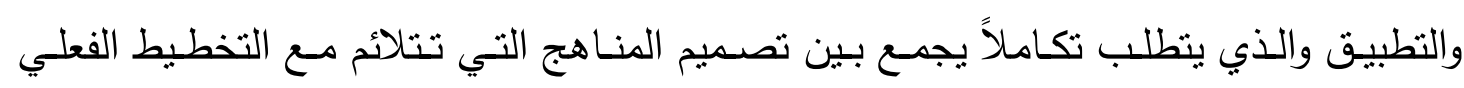

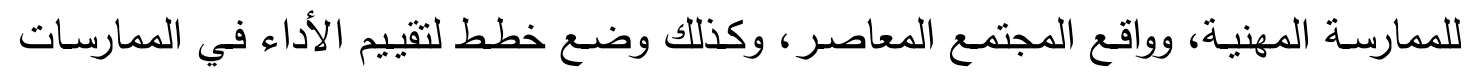
المهنية على كافة مستوياتها الصغرى والكبرى. (Colin, 1978, p. p. 46-59) 
وهذا ما أكدته دراسة (أحمد، 9 . . Y) حينما أثنار إلى أن معاناة الباحثين ناجم عن عدم التوازن بين الجـانبين النظري والتطبيقي الأمر الذي ترتب عليهه نقص في قدراتهم ومهاراتهم البحثية.

إن واقع المجتمع المتغير باستمرار يفرض على مهنة الخدمة الاجتماعية تحدياً وجودياً لإثبات ذاتها، وذلك لن يكون إلا من خلال أمرين الأول: يُعني بمراجعة داخلية وشاملة للنسق

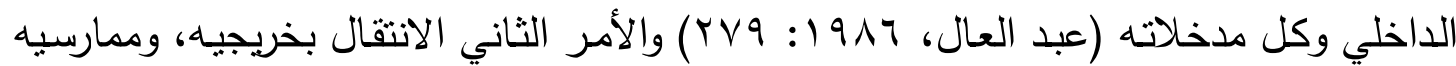
وباحثيه للمستوى الذي يمكنه من العمل التشاركي مع أنساق المجتمع المؤسسية المختلفة والبيئة المحلية المحيطة بها بصورة تتاغيـة وفق آليات محددة توجههم وتحدد لهم الطريق الأمثل لإحداث التأثير والتغيير المرجوة منهم كمتخصصين معنيين بالبعد الاجتماعي البيئي لقضايا التنمية المستدامة. (N. A. S. W, 1990) وهذا ما أكده كل من هيس مكارت وأدوارد مولن(Mccart. Hess, Edward. j. Mullen, 1995) حينما أثـارا إلى أهمية وجود آليات لتعزيز الثراكات بين كل من الممارسين والباحثين لتوليد

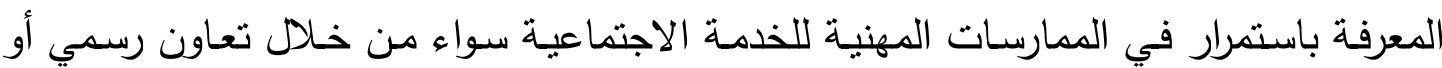
غير رسمي بما يسهم في تطوير المعرفة والممارسة معاً. إن نوليد المعرفة الذي يطالب به هيس ومكارت لن يكون إلا بناء على الجهد التشاركي بين الممارسين والباحثين لأنه بلا شك سينتقل بنا إلى منظور مهني فاعل يدعم المهنة كثريك محوري في إحداث التمية المستدامة المنشودة. وهذا ما أكدته دراسة بعنوان (The role of research in Social Work) حينما أثشارت

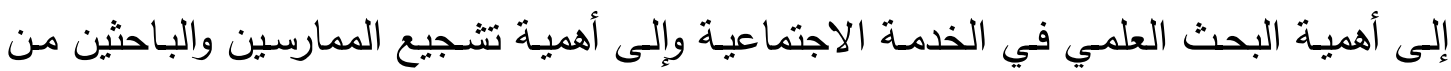

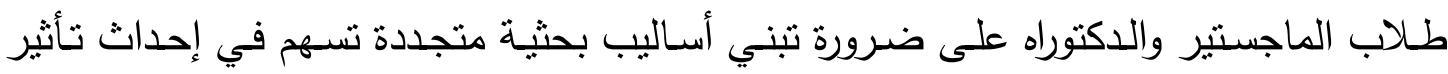
مباشر في القضايا والمشكلات التي يتعاملون معها، وإلى ضرورة الاهتمام بالتدريس الانثروغرافي لمناهج البحث من منظور نقدي، يسهم في تطوير برامج التدخل المهني، ويحسن من مشاريع

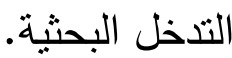

دعم ذلك ستانلي ويتكن (Stanley L. Witkin, 2008) حين أثشار في ورقة عمل له بعنوان علمية الخدمة الاجتماعية، إلى أن فعالية الخدمة الاجتماعية يقاس بمدى نهج ممارسيها المهنيين للأسلوب العلمي عند تتاولهم للقضايا المتمعية المتعلقة بالفئات التي يتعاملون معها. 
وأضاف كريستا فوشيه (Christa Fouche, 2015, p.192) عامل آخر لا يقل أهمية عن سابقيه حينما أكد على أهمية البحوث العلمية المهنية المشتركة للخدمة الاجتماعية لتشكل تكتلات معرفية تسهم في إحداث فارقاً كبيراً في فاعلية المهنة وذلك لقدرة تلك الشراكات على العمل وفق

سيناريوهات واضحة ومحددة تخلق ممارسات فاعلة على مستوى التذخلات المهنية مجتمعياً. في ضوء ما سبق يمكن بلورة مشكلة الدراسة الحالية في قضية رئيسة مؤداها إلى أي مدى تسهم الرسائل العلمية للخدمة الاجتماعية في إحداث تأثيرات نوعية فاعلة في قضايا البعد الاجتماعي البيئي للتتمية المستدامة. ثناتيا:-أهمية الدراسة: يمكن بلورة أهمية الدراسة الحالية في ثلاث نقاط رئيسة هي. 1- أهميـة علميـةة: وذلك بـأثراء الإطـار النظـري المـرتبط بقضـايا التتميـة بصـفة خاصـة والمجتمع بصفة عامـة بنتائج علمية قد تسهم في اعادة النظر لأهمية استغلال البحث العلمي بصورة أكثر فعالية في معالجة قضايا المجتمع في ظل عالم أصبح فيه التحدي الحقيقي لمن يملك المعرفة. ץ- أهميـة مهنيـة: تتمثل في توجيـه اهتمام كل من الباحثين والممارسين على حد سواء بـالتحول من النظرة التقليديـة القاصـرة على العمل منفرداً كل في واد الى اهميـة إدرالك وتعلم ان يكون الباحث مدـارس والمهـارس باحث بمـا يقلل مـن الفجـوة بـين النظريـة والتطبيق.

ب- أهمية مجتمعية: من خلال لفت الا نتباه لسبل انتقاء القضايا الاكثر الحاحاً في المجتمع بالقدر الذي يشعر من خلالله المواطن بالأهميـة من خـلال معالجـة مشكلاته وقضـاياه الفعلية ثالثاً :-أهداف الدراسة: تحددت أهداف الدراسة في هدف رئيسي مؤداه: التعـرف على إسـهامات البحـوث العلميـة للخدمـة الاجتماعيـة وجهودهـا في دعم قضـايا البعد الاجتماعي والبيئي للتنمية المستدامة وانبثق من هذا الهدف أهداف فرعية تمثلت في: 
1- تحديد طبيعة ونوعية البحوث العلمية التي تُعنى بها الخدمة الاجتماعيـة المرتبطة بقضـايا البعد الاجتماعي والبيئي للتتمية المستدامة.

r- التعرف على إسـهامات بحوث الخدمة الاجتماعية في دعم جهود قضـايا البعد الاجتماعي والبيئي للتمية المستدامة.

r- الخروج بآليات لتفعيل دور البحوث العلمية للخدمة الاجتماعية في دعم جهود قضايا البعد الاجتماعي والبيئي للتنمية المستدامة. رابعاً: -تساؤلات الدراسة: تحدد التساؤل الرئيسي للدراسة في الآتي: ما مدى إسهام البحوث العلمية للخدمة الاجتماعية في دعم جهود قضايا البعد الاجتماعي والبيئي للتتمية المستدامة؟ وانبثق من هذا التساؤل عدة تساؤلات فرعية تبلورت في: ا- مـا نوعيـة البحـوث العلميـة التي تهـتم بهـا الخدمـة الاجتماعيـة والمرتبطـة بقضـايا البعـــ الاجثماعي والبيئي للتمية المستدامة؟ r- مـا إسـهامات بحوث الخدمـة الاجتماعيـة في دعم جهود وقضـايا البعد الاجتمـاعي والبيئي للتمية المستدامة؛ ب- ما الآليات التي يمكن من خلالها تفعيل دور البحوث العلمية للخدمة الاجتماعية في دعم جهود قضايا البعد الاجتماعي والبيئي للتتمية المستدامة؟ خامساً: -المنطلقات النظرية للاراسة: تستند الدراسة الحالية على ثلاثة محاور رئيسية تُمتل منطلقات نظرية تحددت في الآتي: المحور الأول: التتمية المستدامة والتحديات التي تواجهها. المحور الثاني: الاندماج والثراكات العلمية كمرتكز لتحقيق التتمية المستدامة. المحور الثالث: البحث العلمي وجهود المارسـة المهنيـة للخدمة الاجتماعيـة في إطسار مفهوم التنمية المستدامة المعاصر . 
المحور الأول:- التنمية المستدامة والتحديات التي تواجهها.

تواجه عملية التتمية المستدامة بالكثير من التحديات التي تحتاج إلى تضافر في الفكر وتوحيد في الجهد والمارسة نظراً لصعوبتها حيث يمكن بلورتها كما حددها المؤتمر الإسـلامي الذي عقد في دورته الثانية عثر بجدة في الآتي: (المؤتمر الإسلامي، ج... 1- الانعكاسـات الاجتماعية والاقتصـادية والبيئية للنزاعـات والحروب الداخلية والإقليمية وعجز المجتمع الدولي عن معالجة أسباب هذه النزاعات على أساس من العدالة. r- تزايد حدة الفقر والجوع وتهديد الأمن الغذائي والتي تتسع رقعتها مع انتشار الأمية وارتفاع عدد السكان والبطالة وتدني الأجور وانخفاض مستوى المعيشـة ومعدلات التدخل وتراكم الديون وفوائدها. r- استمرار معدل الزيادة السكانية والتوسـع الحضري والهجرة من الريف وانتشار ظاهرة التوسع العمراني العشوائي. ع- وطأة التحديات البيئية الكبرى الممثلة في التغيرات المناخية والكوارث الطبيعية. 0- نقص الموارد المائية وندرتها وتدهور نوعيتها أو الصراع عليها. 4- تدهور التربة والأرض الزراعية (حالة التعدي على الرقعة الخضراء وتجريفها). - V تدهور البيئة الساحلية والبحرية واستنزاف الثروة السمكية. 1- أعباء المديونية على العديد من البلدان الإسلامية مما لا يساعد على إيجاد الفرص المواتية والمناخ المناسب لمتطلبات التتمية المستدامة. 9- عدم كفاية مصادر التمويل اللازم لتحقيق تتمية بشرية مستدامة وبناء قدرات، وضعف حجم التبادل التجاري والبيئي والاستثمارات. • 1- تباين في مستوى فعالية الأنظمة التعليمية والبحثية وتطورها في مسايرة التقدم العلمي والتقني ومستلزمات التتمية المستدامة. ا ا - مواجهة تحديات العولمسة الاقتصـادية والإعلاميـة والثقافيـة وضـرورة المحافظـة على التراث الثقافي والإسلامي. r ا - حداثة تجربـة المجتمع المدني وعدم مشـاركته الفعالة في وضـع وتتفيذ استراتيجيات وبرامج التتمية المستدامة. 
المحور الثاني: -الاندماج والثراكات العلمية كمرتكز لتحقيق التنمية المستدامة: إن تحقيق التتمية المستدامة لن يكون إلا بيحوث علمية قائمة على الاندماج والشراكات العلمية محلياً كان أو إقليمياً، ويشترط فيها أن تكون مرتكزة على جانبين: الجانب الأول: -استراتيجية علمية بحثية تكون بمثابة خارطة طريق لتحقيق التتمية المستدامة يكون هدفها:

ا- التركيز على البحوث المستقبلية المتعلقة بظواهر مثنل إدارة المياه وتحسين أنماط الإدارة والحوكمة

r- تطوير عمليات الشراكة المؤسسية مع مؤسسات المجتمع المدني وتأهيل كوادرها. r- إعداد الكوادر البحثية المنتجة التي لا تقتصر جهودها على الوصف والتحليل فقط. (المعهد

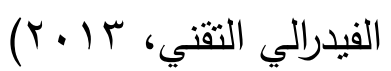
ع- دعم المشاريع البحثية المشتركة إقليمياً. (البار ، 1 . . †) ه- تغيير ثقافة الفكر في البحث العلمي وعلاقته بالتتمية المستدامة بحيث يراعى فيها الآتي: (مجلس البحث العلمي، (1) أ-تحديد أولويات التعامل مع قضايا التنمية المستدامة. ب-اتباع نهج متكامل للتتمية المستدامة بركائزها الأساسية. ج-تحديد التكلفة الناشئة عن الجهود الحالية غير المستدامة. د-إشراك جميع فئات المجتمع من أجل رؤية مشتركة لمستقبل التتمية.

7-تطوير منظومة التشريعات والسياسات المتعلقة بالبحث العلمي. (ربيع، 10 • ب) V-استقطاب المتخصصين في مجال التتمية الاقتصادية والاجتماعية والاستفادة من خبراتها. 1-الاهنمام بتحليل مخرجات برامج التتمية البشرية. (المؤتمر ، الدولي الرابع، 0 ـ ب) 9-توفير الخدمات والبرامج الاستشارية والبحثية والتدريبية لمؤسسات المجتمع المعنية بالتتمية. (أنظر في مؤتمرات حول التتمية المستدامة والبحث العلمي) الجانب الثاني:- توافر المقومات التي تسـاعد على نجاح عملية الاندماج في شراكات علميـة فاعلة تعمل في إطار تكاملي وبروح الفريق وهي منواجدة بالفعل إذ تتشابه الدول

$$
\text { الإسلامية والعربية في: (نحو قضاء عربي للتعليم، } 9 \text {. . r) }
$$




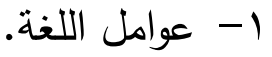

$$
\begin{aligned}
& \text { r- العوامل الاجتماعية والثقافية. } \\
& \text { r- العوامل الطبيعية والجغرافية والامنداد الجغرافي. } \\
& \text { ع- المناخ السياسي بين الدول. } \\
& \text { 0- الخبرات البثرية المتوفرة. }
\end{aligned}
$$

المحقر الثالث:- البحث العلمي وجهود الممارسة المهنية للخدمة الاجتماعية في إطار مفهوم التنمية المستدامة المعاصر:

يتحدد الدور المنوط قيام الخدمة الاجتماعية بـه كأحد العلوم الإنسانية المعنية بالجانب الاجتماعي البيئي للتتمية المستدامة بحثاً وممارسة من خلال مردودها وعائدها المجتمعي ومدى تأثيرهـا الإيجـابي في قضـاياه، بمـا يمكن الجيل الحسالي ويحسـن حياتـه ويضـمن حيـاة ملائمسة

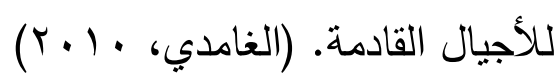
إن حاجة المهنة في ظل مفهوم التمية المستدامة المعاصر يتطلب صياغة النشاطات المهنية الحالية وإعادة التقييم لها، بما يسهم في ابتكار نشاطات وتدخلات مهنية جديدة برؤيـة معاصرة يسهل دمجها في البيئة، تحظى بالقبول الثقافي، والإمكانية المادية، والعدالة الاجتماعية، كما يجب على المهنة إحاطة باحثيها وممارسيها بأهداف التمية المستدامة الـ V عشر التي حددتها الأمم المتحدة لتكون محور اهتمامهم في بحوثهم العملية. وكذلك العمل فى أطلارروية تكاملية بين باحثى وممارسى مهنة الخدمة الاجتماعية بما يدعم الجهود الميدانية فى ارض الواقع وهذا ما بلوره كل من (Hess, Mullen, 1995) ) فى خمسة

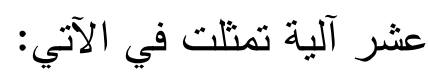
1- تجسير الفجوة بين المعرفة والممارسة. r- الأخذ في الاعتبار التفاوت الفكري والاعتبارات العقلية. r- تحديد الاهتمامات والاحتياجات التثاركية. ع- وجود درجة عالية من الحكم الذاتي والوضوح في الإدارة والمسئوليات بينهما. 0- التواصل الذي يقلل من سوء الفهم. 1- السلطة وتحديد من الذي يتخذ القرار . V - مراعاة الخبرات التعليمية والمهنية فيما بينها. 
1- السعي إلى بناء معرفي من خلال استراتيجيات نعزز الموضوعية وتبعد عن الذاتية. 9- وضوح المفاهيم عند بناء المعرفة بين الممارس والباحث.

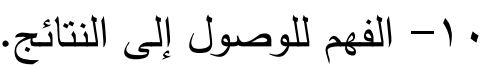
11 - مراعاة الاعتبارات التتظيمية. r ا- مراعاة قواعد السلوك المتفق عليها لتقليل الآراء المتضاربة. با ا - وجود مؤسسات راعية للشراكات التعاونية. ع ا- ربط البحوث بميادين التخطيط والعمل المحلي.

10-استخدام الباحث للمشورة لتعزيز الممارسة.

سادساً: -الاستراتيجية المنهجية للاراسة:

ا ا-نوع الدراسة:

لما كانت الدراسة تهدف إلى تحديد صور وطبيعة البحوث العلمية للخدمة الاجتماعية، وإسهاماتها في دعم جهود قضايا البعد الاجتماعي البيئية للتنمية المستدامة وفق تحليل مضمون

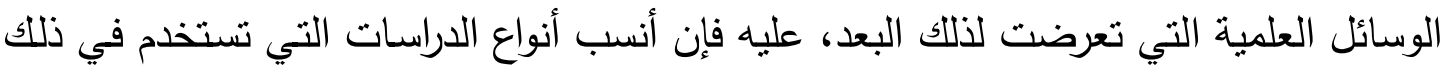

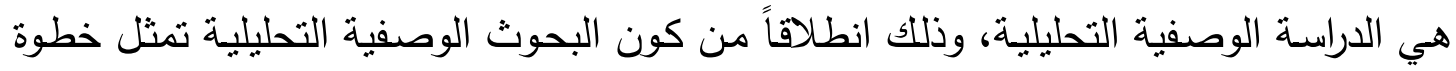

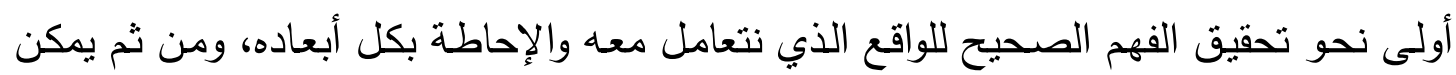

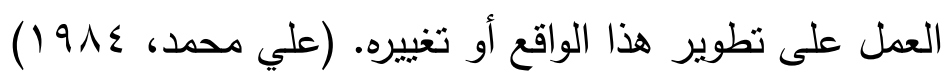
r-المنهج المستخدم: - r اعتمدت الدراسـة الحاليـة على منهجـي تحليل مضـمون الرسـائل العلميـة ومـنهج المسـح الاجتماعي بالعينة العدية من خلال: أ- تحديد عمدي لمـادة التحليل موضوع الدراسـة والمتمثلة في الرسائل العلمية لقسم التخطيط والتتمية بكلية الخدمة الاجتماعية جامعة الفيوم والتي بلغت ( • 9) رسالة ماجستير ، و(r ع) رسالة دكتوراه وهو المبرر المنطقي الأول لأن هذا القسم المعني بقضايا البعد الاجتماعي ولئي والبيئي للتنمية المستذامة بحكم رؤيته ورسالته العلمية. ب-ثم قام الباحث بعمليـة انتقائية عمديـة أخرى لأبرز الرسـائل التي تعرضت لقضـايا البعد

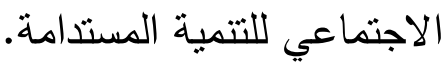


ج-أخذ الباحث أيضاً بعين الاعتبار عند عملية الانتقائية تلك البعد الزمني للرسائل مادة التحليل بحيث تكون قريبة من مزامنتها لبدء ظهور مصطلح التتمية المستذامة الذي ظهر في فترة التسعينات (r9 99 (م) مع بدء اعتماد المفهوم في مؤتمر الأرض بالبرازيل وإن كانت بداياته

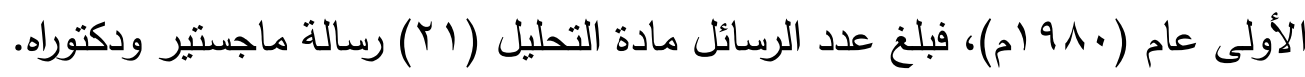
ب-أدوات جمع البيانات: اعتمـد الباحث على دليـل لتحليـل محتوى الرسـائل العلميـة التي اهتمـت بقضـايا البعد الاجتماعي والبيئي للتتمية المستدامة، قام الباحث بتصميمه (طعيمة، وآخرون، 9AV I ) تمثلت أهم مؤشراته في الآتي: المحور الأول: البيانات الأولية لرسائل الماجستير والدكتوراه بقسم التخطيط والتتمية. المحور الثاني: مدى تـاول الرسـائل العلميـة للخدمـة الاجتماعيـة لاهتمامـات البعد الاجتمـاعي البيئي للتمية المستدامة. المحور الثالث: إبـهامات الرسـائل العلميـة للخدمـة الاجتماعيـة في دعم جهود وقضـايا البعد الاجتمـاعي والبيئي للتتميـة المسـتدامة. روعـي فيسه عرضـه على عدداً مـن المحكمين لأجراء الصدق (الظاهري)

\section{؛ -مجالات الدراسة:}

أ -المجال المكاني: ثم إجراء الدراسة في ج· م. ع. جامعة الفيوم -كلية الخدمة الاجتماعية. ب-المجال البشري: اعتمدت الدراسـة على رسـئل الماجستير والدكتوراه لباحثين ومعيدي قسم التخطيط والتتمية بكلية الخدمة الاجتماعية، جامعة الفيوم.

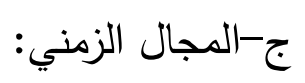

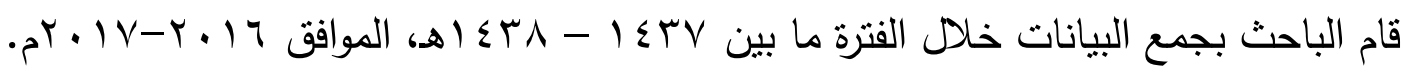
د-المعالجات الإحصائية: - د

اعتمدت الدراسـة على التكرارات والمتوسـات الحسـابية والنسـب المئويـة، وفـق طبيعـة تحليل المحتوى والذي يتسم بطابع التحليل الكيفي أكثر من الكمي (الرقمي). 
سابعاً:-- نتائج الدراسة:

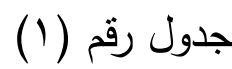

يوضح ميزان التقدير الرقمي لدليل تحليل محتوى الرسائل العلمية

وحدات التحليل للموضوعات المرتبطة بالتتمية المستدامة في الخدمة الاجتماعية

$r=\dot{0}$

\begin{tabular}{|c|c|c|}
\hline 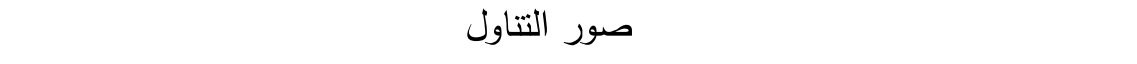 & 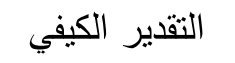 & 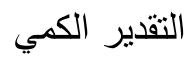 \\
\hline عدم اثتمال الرسائل العلمية على المكونة في موضوع التتمية المستدامة نهائياً. & ضعيف جدا & صفر \\
\hline اشتمال الرسائل العلمية على المكونة ولكن لم يتم تتاولها لموضوعات التتمية المستدامة. & ضعيف & 1 \\
\hline تتاول الرسائل العلمية الجزئية واحدة من المكونة الخاصة بالتتمية المستدامة. & أقل من متوسط & r \\
\hline تتاول الرسائل العلمية لجزئيتين من أجزاء المكونة الخاصة بالتتمية المستدامة. & 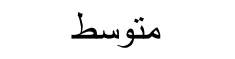 & $r$ \\
\hline تتاول الرسائل العلمية لثلاث جزئيات من أجزاء المكونة الخاصة بالتنمية المستدامة. & أعلى من متوسط & $\varepsilon$ \\
\hline تتاول الرسائل العلمية لأربعة أجزاء من أجزاء المكونة الخاصة بالتتمية المستدامة. & 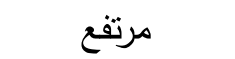 & 0 \\
\hline تتاول الرسائل العلمية لجميع أجزاء المكونة المتعلقة بالتتمية المستدامة. & مرتفع جداً & 7 \\
\hline
\end{tabular}

(*)المقصود بالمكونـة هي المؤشر والذي يقصده الباحث في أحد محاور وموضوعات التتمية

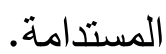

سادساً: نتائج الدراسة:

النتائج الخاصة بالاجابة على التساؤل الفرعي الأول المتعلق بتوصيف الرسائل العلمية

التي تعرضت لقضايا البعد الاجتماعي والبيئي في التتمية المستدامة.

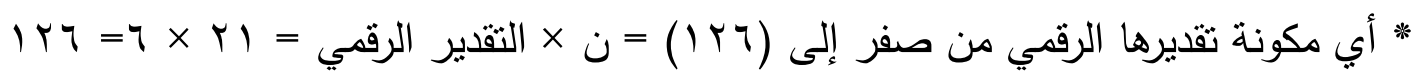




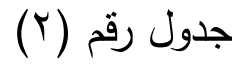

يوضح مستوى الرسائل العلمية ومكان إجراء الرسالة

\begin{tabular}{|c|c|c|c|c|c|c|c|}
\hline \multicolumn{2}{|c|}{ الإجمالي } & \multicolumn{2}{|c|}{ رسائل الدكتوراه } & \multicolumn{2}{|c|}{ رسائل الماجستير } & 1 & r \\
\hline$\%$ & ك & $\%$ & ك & $\%$ & ك & & \\
\hline $1 \varepsilon, r$ & $r$ & & & $\% \backslash \varepsilon$ & $r$ & القاهرة & 1 \\
\hline$\varepsilon, V$ & 1 & & & $\% \circ$ & 1 & الدقهلية & $r$ \\
\hline 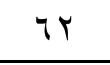 & $1 \pi$ & $\% 9,0$ & $r$ & \%०r & 11 & 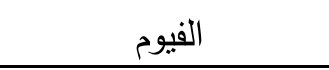 & $r$ \\
\hline $1 \varepsilon, \Gamma$ & $r$ & $\% 9,0$ & $r$ & $\% \circ$ & 1 & على مستوى الجمهورية & $\varepsilon$ \\
\hline$\varepsilon, V$ & 1 & $\% 9,0$ & 1 & & & سوهاج & 0 \\
\hline$\% 1 .$. & r & $\% \curlyvee \varepsilon$ & 0 & $\% \vee 4$ & 17 & المجموع & \\
\hline
\end{tabular}

يتضح من الجدول السابق الأتي: وجد أن مسنوى رسائل الماجستير كوحدات تحليل في

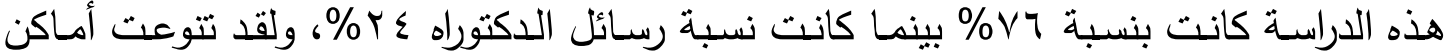
إجراء وتطبيق هذه الرسائل، واحتلت محافظة الفيوم الترتيب الأول بنسبة rآ\% ثقريباً وتعتبر تلاك النسبة طبيعية وذلك من منطلق أن لائحة الكلية تنص على أن تطبق أي رسالة علمية في

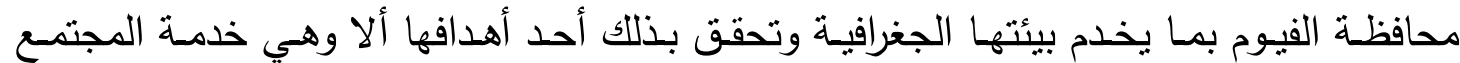
المحيط بها من خلال معالجة قضاياه ومشكلاته بما يسهم في تتمية إقليم الفيوم وإن لم تتوافر القضية البحثية في إقليم الفيوم فيحق للباحث النطبيق في المكان الآخر الذي يحتاج إلى دراسة مشكلاته وقضاياه، وبلغت نسبة تلك الدراسات التي طبقت في محافظات أخرى ^ب\% تقريباً. 


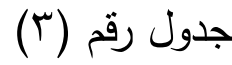

يوضح تاريخ ومكان نشر الرسائل العلمية وحدات التحليل للدراسة

\begin{tabular}{|c|c|c|c|c|c|c|c|c|c|}
\hline \multicolumn{2}{|c|}{ الإجمالي } & \multicolumn{2}{|c|}{$e^{r+10-r \cdot 1 . ~}$} & \multicolumn{2}{|c|}{ ع... } & \multicolumn{2}{|c|}{ } & \multirow{2}{*}{ مكان النشر } & \multirow[t]{2}{*}{ 5 } \\
\hline$\%$ & ك5 & $\%$ & 5) & $\%$ & s) & $\%$ & 5] & & \\
\hline $1 \ldots$ & Y & $v 1,0$ & 10 & rT,A & 0 & $\varepsilon, V$ & 1 & كلية الخدمة الاجتماعية - & 1 \\
\hline$\% 1 \ldots$ & Y & & 10 & & 0 & & 1 & المجموع & \\
\hline
\end{tabular}

يتضـح من الجدول السـابق أن جميع الرسـائل العلمية سواء كانت ماجستير أو دكتوراه كان مكان نشرها هو كلية الخدمة الاجتماعية جامعة الفيوم، في حين تفاوت تواريخ إجازة هذه الرسـائل وهذا وضـع طبيعي بحكم الاختيار ألعمدي من قبل الباحث بيدء اختيار الرسائل مادة التحليـل والتـي راعى فيها الباحث أن يتزامن سـنة اختيارهـا مـع بـده الاهتمـام بقضـايا التتميـة المستدامة وتحديداً قضايا البعد الاجتماعي والبيئي. جدول رقم (飞) يوضح نوع الدراسات المستخدمة داخل الرسائل العلمية التي تتاولت موضوعات متعلقة بالتتمية المستدامة

\begin{tabular}{|c|c|c|c|c|c|c|}
\hline \multirow{2}{*}{ 䍏 } & \multicolumn{2}{|c|}{ ال الإجمالي } & رسائل دكتوراه & رسائل ماجستير & نوع الدراسة ل & ? \\
\hline & $\%$ & 5 & ك5 & 5] & & \\
\hline- & - & - & - & - & دراسات استطلاعية كثفية & 1 \\
\hline 1 & $\varepsilon \vee\rceil$, & 1. & - & 1. & دراسات وصفية تحليلية & r \\
\hline Y & 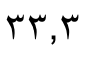 & $V$ & $r$ & 0 & دراسات تقويمية (تقيييمية) & $\Gamma$ \\
\hline$r$ & 19,1 & $\varepsilon$ & $r$ & r & دراسات شبه تجريبية (عائد تداخل مهني) & $\varepsilon$ \\
\hline & $1 \ldots$ & r & $\varepsilon$ & IV & 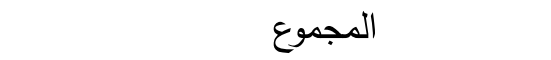 & \\
\hline
\end{tabular}

يتضح من الجدول السابق أن السمة الغالبة على نوعية الرسائل العلمية كانت ثتثمي إلى

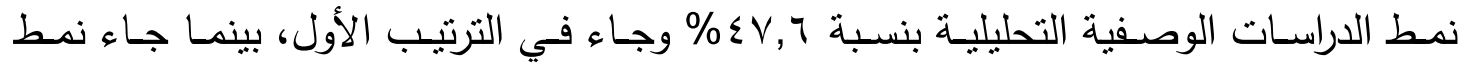


الدراسات التقويمية في الترتيب الثاني بنسبة r,rr\%، وجاء نمط الدراسات شبه التجربيية (أو دراسـات عائد التدخل المهني) في الترتيب الثالث والأخير بنسبة (9 (9\%، وهو الأمـر الذي يعطي دلالة إلى الحاجة الملحة إلى توجيه الباحثين للأخذ بنمط الدراسات شبه التجربيية لأنـه الأكثر تأثيراً وفعالية في إحداث تغيير مؤثر في البيئة الجغرافية محور التدخل، كما أنه قد يفرز لنا نماذج ومبادرات وبرامج وجهود تدخل يمكن أن يحتذي بها في القضـايا المشـابهة للقضـايا الحالية.

بيد أن ها الأمر يتطلب إعداداً خاصاً لتتمية مهارات الباحثين وتدريبهم على هذا النوع من الدراسات وكذلك إعادة النظر في إستراتيجية البحث العلمي الحالية من قبل أقسام الدراسات العلميـة بالكليات بمـا يدعم ويوجـه باحثيـه لتبني نوع الدراسـات في إطـار تعـاون ممـارس يخدم قضايا التتمية المستدامة.

جدول رقم (0) - (0) - (0)

يوضح توصيف لأماكن تطبيق الرسائل العلمية ميدانياً

\begin{tabular}{|c|c|c|c|c|c|c|c|}
\hline \multicolumn{2}{|c|}{ 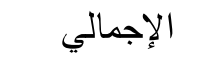 } & \multicolumn{2}{|c|}{ رسائل دكتوراه } & \multicolumn{2}{|c|}{ رسائل ماجستير } & \multirow[t]{2}{*}{ 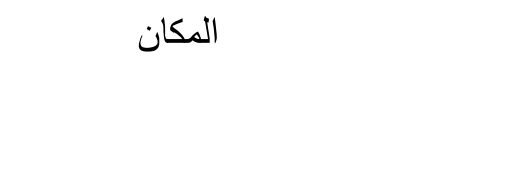 } & \multirow[t]{2}{*}{ s } \\
\hline$\%$ & ك & $\%$ & ك & $\%$ & ك & & \\
\hline$\varepsilon, V$ & 1 & & & & 1 & جمعيات تتمية المجتمع الحكومية & 1 \\
\hline$Y \wedge, \uparrow$ & 7 & & & & 7 & جمعيات أهلية بالمناطق الريفية & r \\
\hline$\varepsilon \vee, \uparrow$ & 1. & & r & & V & جمعيات أهلية بالمناطق الحضرية الفقيرة & r \\
\hline 9,0 & r & & & & r & مؤسسات تعليمية & $\varepsilon$ \\
\hline 9,0 & r & & r & & & المدارس الحقلية والصديقة & 0 \\
\hline$\% 1$. & Y) & & 0 & & 17 & المجموع & \\
\hline
\end{tabular}

يتضح من الجدول السابق أن أكثر الأماكن التي طبقت فيها رسائل الماجستير والدكتوراه كانت

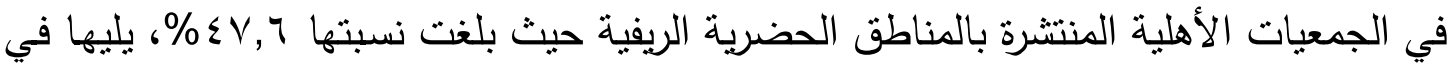

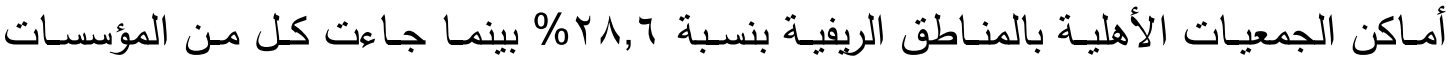


التعليميـة، والمدارس الحقليـة والصديقة في الترتيـب الثالث بنسبة 9,0\% لكل منهمـا، وجـاءت الجمعيات الحكومية في الترتيب الأخير بنسبة V, \&\&. ويمكن أن نرجع تفسير ذلك إلى النشاط الواضـح للجمعيات الأهلية سواء في المناطق الحضـرية أو الريفيـة والدور الهام الذي تقوم بـه في مسـاندة جهوده الدولـة في عمليـة الرعايـة والتتمية الاجتماعية.

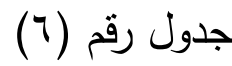

يوضح للفئات المعنى بها داخل الرسائل العلمية للخدمة الاجتماعية (مجتمع الدراسة) الدرجة الكلية للبعد جr الدرجة الكلية للمؤشر الفرعي بوداج

\begin{tabular}{|c|c|c|c|}
\hline$\%$ & S & 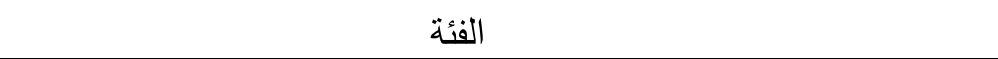 & 5 \\
\hline 9,0 & r & المرأة والمرأة المعيلة. & 1 \\
\hline$\varepsilon, V$ & 1 & أطفال الشوارع. & $r$ \\
\hline$\varepsilon, V$ & 1 & الفتيات الصغيرات المقبلات على الزواج. & r \\
\hline 19,1 & $\varepsilon$ & الأسر الفقيرة المستحقة للاعم. & $\varepsilon$ \\
\hline $1 \leqslant, r$ & r & تعليم الفتيات. & 0 \\
\hline$\varepsilon, V$ & 1 & الطفل العامل. & 7 \\
\hline$\varepsilon, V$ & 1 & المعاقين. & $v$ \\
\hline 9,0 r & r & المستفيدين من برامج الخدمات التعليمية (الفصل الواحد - المدارس الحقلية) & $\wedge$ \\
\hline $9,0 Y$ & r & المستفيدين من التدريب وتتمية الموارد البشرية. & 9 \\
\hline$\varepsilon, V$ & 1 & المستفيدين من برامج الإقراض. & 1. \\
\hline$\varepsilon, \vee$ & 1 & الإناث المستقيدة بمن خدمات الرعاية الصحية. & 11 \\
\hline 9,0 Y & r & القضايا البيئية والاحتباس الحراري والإصحاح البيئي. & it \\
\hline$\% 1 \ldots$ & r) & & 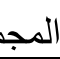 \\
\hline
\end{tabular}

يتضح من الجدول السابق أن أكثر الفئات التي تعرضت لها الرسائل العلمية هي الأسرة الفقيرة المستحقة للدعم بنسبة ع,9 1\%، تلتها في الترتيب الرسائل التي تعرضت لقضية تعليم

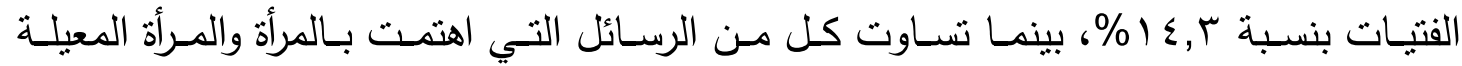
والمستقيدين من الخدمات التعليمية والتدريب وتتمية الموارد البشرية وقضـايا البيئة في الترتيب الثالث بنسبة 9,or\%، ثم جاء في الترتيب الرابع اهتمام الرسائل بفئات أطفال الثوارع والفتيات الصغيرات المقبلات على الزواج والطفل العامل، المعاقين، والمسـقفيدين مـن برامج الإقراض وخدمات الرعاية الصحية بنسبة V, ₹\& ويخلص الباحث من ذلك إلى أن هناك حالة من التفتيت وعدم التركيز على قضايا بعينها وهذا يعطي دلالة على عدم وجود إستراتيجية بحثية واضحة تعني بقضايا البعد الاجتماعي. 


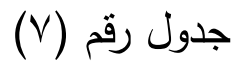

يوضح التأصيل النظري للتتمية المستذامة داخل الرسائل العلمية للخدمة الاجتماعية

\begin{tabular}{|c|c|c|c|}
\hline$\%$ & s & مدى تتاول الرسائل العلمية للمفاهيم والأسس المرتبطة بالتتمية المستدامة & 5 \\
\hline $1 \varepsilon, r$ & r & الأسس النظرية للتنمية المستدامة. & 1 \\
\hline r & $\mathrm{v}$ & الجمعيات الأهلية وإسهاماتها في التتمية المستدامة. & r \\
\hline $1 \varepsilon, \Gamma$ & r & 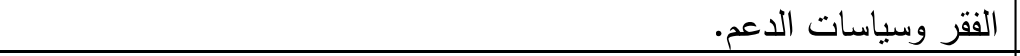 & r \\
\hline rT, r & $\mathrm{v}$ & ت تتمية الموارد البشرية وبناء القدرات. & $\varepsilon$ \\
\hline$\varepsilon, \mathrm{V}$ & 1 & الإصحاح البيئي والتنمية المستدامة. & . \\
\hline$\% 1 .$. & r) & & المج \\
\hline
\end{tabular}

يتضح من الجدول السابق المتعلق بتتاول الرسائل العلمية للتأصيل النظري لقضايا البعد

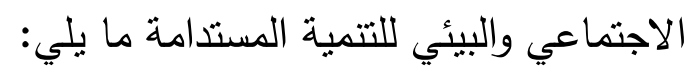

1- الاعتمـاد على جمع مادة نظرية ترتبط بالتتمية وقضاياها دون التعمق والتحليل والاستفادة

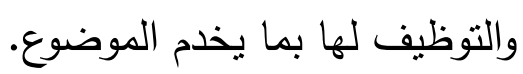

r- بالرغم من أن التأصيل النظري تركز غالبيته على كل من الجمعيات الأهلية وتتمية الموارد

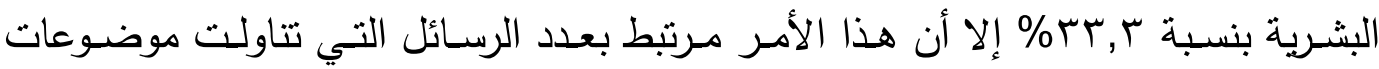

مرتبطة بها.

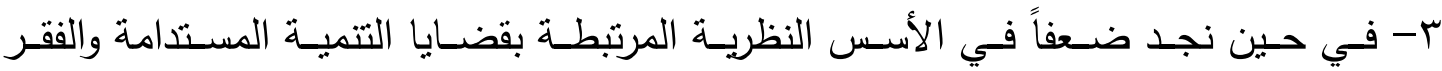

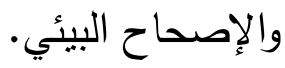

جدول رقم (^)

يوضح المداخل والنظريات العلمية للخدمة الاجتماعية المستخدمة

\begin{tabular}{|c|c|c|c|}
\hline$\%$ & s & الأسس والدداخل والاستراتيجيات النظرية في التتمية & 5 \\
\hline 9,0 & $r$ & شبكات الأمان الاجتماعي & 1 \\
\hline 9,0 & r & الممارسة العامة & r \\
\hline $1 \varepsilon, r$ & $r$ & التمكين في الخذمة الاجتماعية & r \\
\hline 19 & $\varepsilon$ & الثراكات المجتمعية & $\varepsilon$ \\
\hline$\varepsilon, \Lambda$ & 1 & حل المشكلة & 0 \\
\hline$r \wedge, 0$ & 1 & التخطيط الاجتماعي & 1 \\
\hline$\varepsilon, \Lambda$ & 1 & التشبيك الاجتماعي & $v$ \\
\hline$\varepsilon, \Lambda$ & 1 & التأهيل المرتكز على المجتمع & $\Lambda$ \\
\hline$\varepsilon, \Lambda$ & 1 & الممارسة المهنية & 9 \\
\hline$\% 1 .$. & r) & المجموع & \\
\hline
\end{tabular}

مع قضايا وموضوعات التتمية المستدامة 
يتضح من الجدول السابق أن كل الرسائل العلمية مادة التحليل لم تعتمد على مداخل أو نماذج علمية محددة في تفسيرها للقضايا المتتاولة بحثياً بالرغم من أن نماذج التتمية واضحة

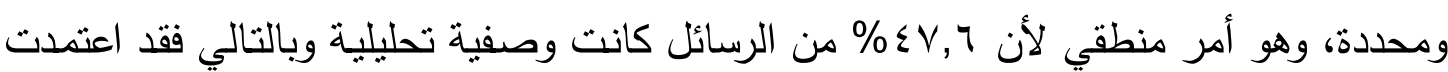

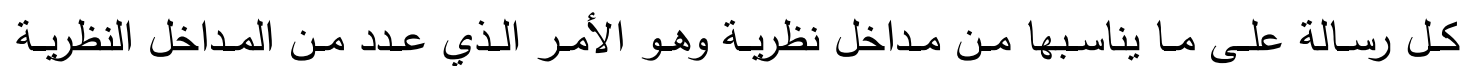

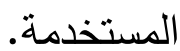

كما أن قلة استخدام نمط الدراسات شبه التجريبية (عائد التدخل المهني) أثر كثيراً في إمكانية تحديد نموذج علمي فعال يمكن تطبيقه أو ثبت نجاحه في قضايا التتمية وبالتالي يمكن تعميمه، وهو الأمر الذي أثر بدوره على عدم وجود مبادرات وبرامج مهنية ناجحة يمكن تطبيقها في قضايا تتموية مشابهة للقضايا المطروحة في تلك الرسائل. نتـائج التشـاؤل الفرعي الثـاني الخـاص بـ "مـدى تتـاول الرسـائل العلميـة للخدمـة الاجتماعيـة

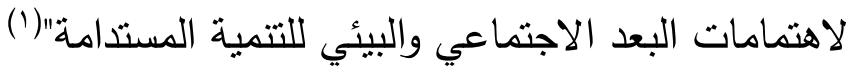

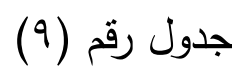

خاص بـ المؤشر الأول المتعلق بمدى تتاول الرسائل العلمية لقضايا التعليم

\begin{tabular}{|c|c|c|c|c|c|}
\hline ملاحظات & 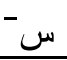 & $\%$ & 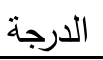 & صور التتاول & 5 \\
\hline \multirow[t]{2}{*}{ 0 } & - & - & - & مدى تتاول الرسائل العلمية لقضايا التعليم الأساسي & 1 \\
\hline & 1 & $\varepsilon, \Lambda$ & 7 & والتسرب المدرسي تـاول الرسـئل العلميـة لقضـايا محو الأميـة وتعليم الكبار & r \\
\hline الفرعي = درؤشر & - & - & - & نشر الوعي المتاول الرسائل العلمية لدور مؤسسات المجتمع المدني في & r \\
\hline الكلية= ـرجة المؤشر & 1 & $\varepsilon, \Lambda$ & 7 & والمدارس تتـاول الرسـائل العلميـة لمبادرات وتجارب الفصل الواحدـ- & $\varepsilon$ \\
\hline \multirow[t]{2}{*}{$r r, \Lambda=\%$} & r & $9, \S$ & ir & تعليم الفتيات. تناول الرسائل العلمية لجهود الخدمة الاجتماعية في دعم & 0 \\
\hline & 1 & $\varepsilon, \wedge$ & 7 & مدى تتاول الرسائل العلمية لبرامج التوعية والتعبئة المجتمعية & 7 \\
\hline
\end{tabular}

يتضح من الجدول السابق أن درجة تتاول الرسائل العلمية لقضايا التعليم كأحد مؤشرات

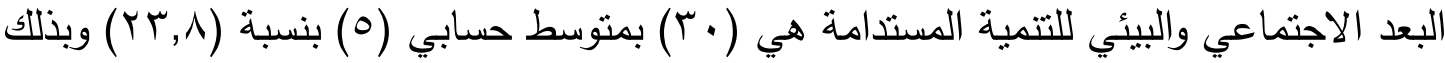
تحدد مدى تعرض الرسائل العلمية لقضايا التعليم في البعد الاجتماعي والبيئي للتنمية المستدامة 
بتقدير كيفي (أقل من المتوسط) وفق دليل التحليل، أما عن تتاول الرسائل العلمية لكل مؤشر فرعـي داخـل هـذا المؤشـر الكلـي فقد اتضـح أن درجـة تتـاول الرسـائل العلميـة لجهـود الخدمـة الاجتماعية من دعم تعليم الفتيات هي (Y Y) درجة بمتوسط حسابي (Y) ونسبة (ع,9\%) وبذلك تحدد مدى تتاول الرسائل العلمية لجهود الخدمة الاجتماعية في تعليم الفتيات بتقدير كيفي (أقل من المتوسط) وجاء في الترتيب الأول، في حين جاء في الترتيب الثاني كل من الرسائل التي اهتمت بقضايا محو الأمية وتعليم الكبار والتسرب المدرسي، والمدارس الصديقة والحقلية وبرامج

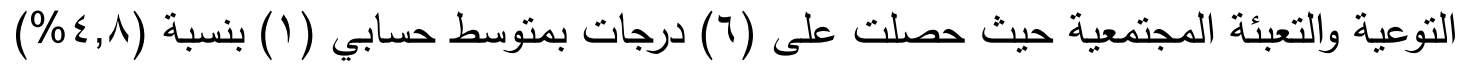
بثقدير كيفي (ضعيف). هذا ويمكن أن نستخلص من النتائج السابقة ما يلي: - بالرغم من أن غالبية الرسائل العلمية كان هدفها الأساسي ينصب على دراسة التعليم كأحد القضايا الهامة في البعد الاجتماعي البيئي للتتمية المستدامة إلا أن هذه الرسائل لم تتعدى أهدافها سوى التطرق بصورة أقل من المتوسط لقضايا هذا البعد داخل منن الرسائل وأنها لم تثعمق بالصورة المرجوة منها. - - كما أن هناك موضوعات لم تتطرق إليها الرسائل مثل قضايا التعليم الأساسي، وقضـايا مؤسسات المجتمع المدني ودورها في نشر الوعي وتعليم الفتيات.

$$
\text { جدول رقم ( ) (1) - (1) }
$$

خاص بالمؤشر الفرعي الثاني المتعلق بـ مدى تتاول الرسائل العلمية لقضايا الوعي الاجتماعي

\begin{tabular}{|c|c|c|c|c|c|}
\hline ملاحظات & س- & $\%$ & الدرجة & صور التتاول & م \\
\hline \multirow{3}{*}{ 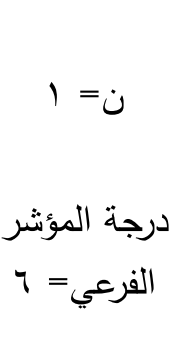 } & - & - & - & والتثقيف الصدى تتـاول الرسـائل العلميـة لموضـوعات تتعلق بسوء التغذيـة & 1 \\
\hline & - & - & - & 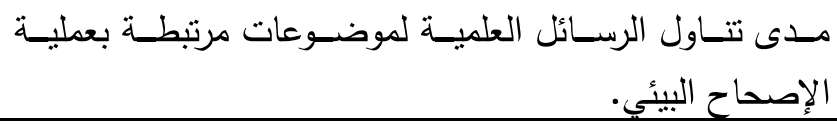 & r \\
\hline & - & - & - & المياه النقية. & r \\
\hline \multirow[t]{3}{*}{ درجة المؤشر } & - & - & - & مدىى تتـاول الرسـائل العلميـة لموضـوعات حول سبل الحـد من & $\varepsilon$ \\
\hline & - & - & - & والتوعية لموارد البيئة الطبيعية. & 0 \\
\hline & 1 & $\% 乞, \wedge$ & 7 & مداجحة تلـاول الرسائل العلميـة لتدخلات مهنيـة أو تجارب عالميـة & 7 \\
\hline
\end{tabular}


يتضـح من الجدول السـابق أن درجة تــاول الرسـئل العلميـة لقضـايا الوعي الاجتمـاعي كأحد مؤشرات البعد الاجتماعي والبيئي للتتمية المستدامة هي (T) بمتوسط حسابي (1) بنسبة

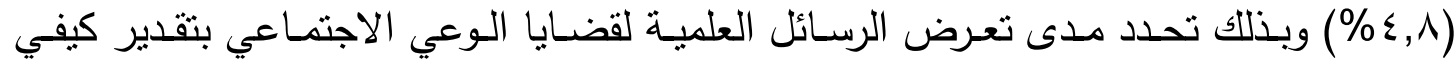
(ضعيف) وفق دليل التحليل، أما عن تتاول الرسائل العلمية لكل مؤشر فرعي داخل هذا المؤشر الكلي لم تحصل سوى الرسائل العلمية المتعلقة بعملية مشكلات التلوث البيئي على (T) درجات

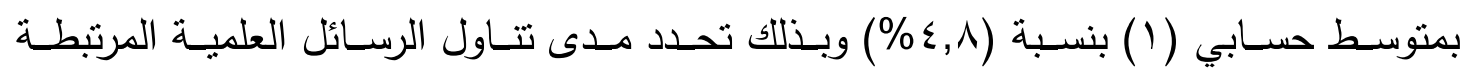
بمشكلات التلوث البيئي على تقدير كيفي (ضعيف). في حين لم تتعرض أي رسـائل مـن الماجستير أو الدكتوراه لقضـايا البعد الاجتمـاعي والبيئي المرتبطة بـ (سوء التغذيـة-التثقيف الصـي -ترشيد المياه النقية وسبل الحفاظ عليهاالتوعية بسبل الحد من استنزاف الموارد الطبيعية) وهو الأمر الذي يتطلب إعادة النظر في طبيعة ونوعية الموضوعات البحثية التي يجب دراستها بما يخدم عملية التتمية المستدامة. جدول رقم (11) - (1) - (1)

خاص بالمؤشر الفرعي الثالث المتعلق بـ مدى تتاول الرسائل العلمية لموضوعات العدالة الاجتماعية للفئات السكانية المعرضة للخطر

\begin{tabular}{|c|c|c|c|c|c|}
\hline ملاحظات & 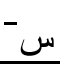 & $\%$ & 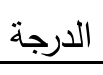 & صور التناول & r \\
\hline \multirow[t]{2}{*}{ ن = = 1. } & $\varepsilon$ & $\% 19$ & r乏 & تحسين نوعية الحياة. & 1 \\
\hline & r & $1 \varepsilon, r$ & 11 & مدى تتاول الرسائل العلمية لقضايا المرأة (المرأة المعيلة) & r \\
\hline \multirow[t]{4}{*}{ الفرجة المؤشر } & r & 9,0 & IT & 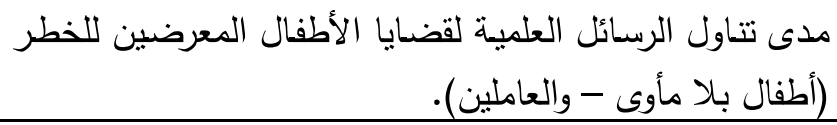 & r \\
\hline & - & - & - & ومشكى تــاول الرسـائل العلميــة لقضــايا كبـار السـن واحتياجـاتهم & $\varepsilon$ \\
\hline & 1 & $\varepsilon, \wedge$ & 7 & مدى تتاول الرسائل العلمية لمشكلات المعاقين. & ○ \\
\hline & - & - & - & الخاصدى تنـاول الرسـائل العلميـة لقضـايا الدمج لذوي الاحتياجـات & 7 \\
\hline
\end{tabular}

يتضـح من الجدول السـابث أن درجـة تتاول الرسـائل العلميـة لقضـايا العدالة الاجتماعيـة للفئات السكانية المعرضة للخطر كأحد مؤشرات البعد الاجتماعي والبيئي للتتمية المستدامة هي

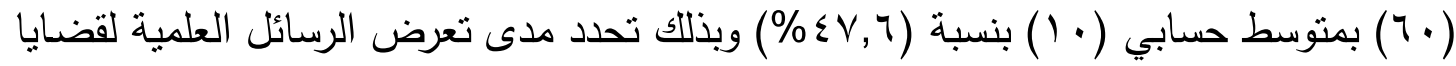
العدالة الاجتماعية للفئات السكانية المعرضـة للخطر بتقدير كيفي أقل من المتوسط وفق دليل التحليل، أما عن تتاول الرسائل العلمية لكل مؤشر فرعي داخل هذا المؤشر الكلي فقد أتضح أن 
درجة تـاول الرسـائل العلميـة للجماعات الفقيرة المهثمة وموضـوعات تحسين نوعيـة الحياة قد

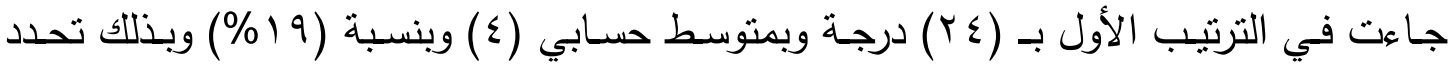
تتاول الرسـائل العلمية لهذا المؤشر بتقدير كيفي (أعلى من المتوسط)، بينما جاء في الترتيب الثاني الرسائل العلمية المرتبطة بقضايا المرأة والمرأة المعيلة بـ (1 I) درجة وبمتوسط حسابي (ب) بنسبة (r,ع ا \% ) وبلك تحدد تتاول الرسائل العلمية لهذا المؤشر بتقدير كيفي (متوسط) في حين جاء في الترتيب الثالث الرسـئل العلميـة التي تتاولت القضـايا المعيشية والأطفال المعرضين للخطر (سواء كانوا أطفالاً بلا مأوى أو الأطفال العاملين) بحصولها على (Y I) درجة بمتوسط حسابي (r) بنسبة (9,0\%) وبذللك تحدد تتاول الرسائل العلمية لهذا المؤشر بتقدير كيفي (أقل من المتوسط)، وأخيراً جاءت الرسائل العلمية التي تعرضت لمشكلات المعاقين في الترتيب الرابع لحصولها على (7) درجات بمثوسط حسابي (1) بنسبة (^,^ع\%) وبذللك تحدد تتاول الرسـئل لهذبا المؤشر بتقدير كيفي (ضعيف) .

بينما لم تتعرض أي من الرسائل العلمية لقضايا كبار السن، وقضايا الدمج لذوي الفئات الخاصة وهو الأمر الذي يعني ضرورة وضعها في الاهتمام في دراسات بحثية قادمة.

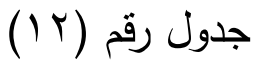

خاص بالمؤشر الفرعي الرابع المتعلق بـ مدى تتاول الرسائل العلمية لقضايا الرعاية الاجتماعية

\begin{tabular}{|c|c|c|c|c|c|}
\hline ملاحظات & 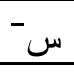 & $\%$ & 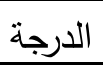 & 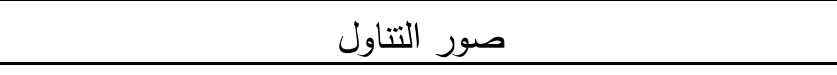 & 5 \\
\hline \multirow{3}{*}{ ن } & 1 & 1 & 7 & مدى تتاول الرسائل العلمية لقضايا الرعاية الصحية. & 1 \\
\hline & - & - & - & مدى نتاول الرسائل العلمية لقضايا حقوق المرضى. & r \\
\hline & - & - & - & مدى تتاول الرسائل العلمية لقضايا التأمين الصحي بأنواعه. & r \\
\hline \multirow[t]{3}{*}{ درجة المؤشر } & - & - & - & مداى نتـاول الرسـائل العلميـة لسبل الارتقاء بالرعايـة الصـحية & $\varepsilon$ \\
\hline & - & - & - & والوقاية من الأمراض. تلـاول الرسـائل العلميـة لقضـايا الحمايـة والوعي الصـحي & ० \\
\hline & - & - & - & مدى تتاول الرسائل العلمية لقضايا لسياسات الرعاية الصحية. & 7 \\
\hline
\end{tabular}

يتضـح من الجدول السـابق أن درجة تتاول الرسائل العلمية لقضـايا الرعايـة الاجتماعية

كأحد مؤشرات البعد الاجتماعي والبيئي للتمية المستدامة هي (T) بمتوسط حسابي (1) بنسبة

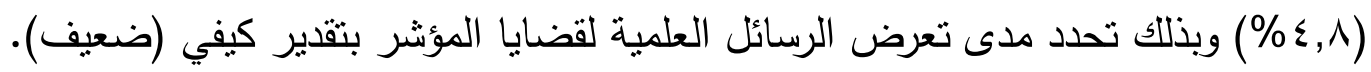
هذا ويمكن أن نستخلص مدا سبق مـا يلي: أن بـاقي المؤشرات الفرعيـة لهذا المؤشر العام لم تحظى باهنمام الباحثين إذ لم تتعرض أي من الرسائل العلمية مادة التحليل تخصصاً 
وزمنياً لأي من الموضوعات المتعلقة بقضايا حقوق المرضى والتأمين الصحي، وسبل الارتقاء بالرعاية الصحية والوعي الصحي، ومناقثـة سياسات الرعاية الصحية، وهو الأمر الذي يتطلب معه إعادة النظر في توجيه البحث العلمي لتلك القضايا بما يخدم تفعيل البحث العلمي في هذا البعد من التتمية المستدامة.

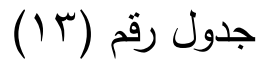

خاص بالمؤشر الفرعي الخامس المتعلق بـ مدى تتاول الرسائل العلمية لقضايا التثمية البشرية والمشاركة الشعبية

\begin{tabular}{|c|c|c|c|c|c|}
\hline ملاحظات & س - & $\%$ & 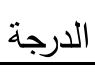 & صور التتاول & r \\
\hline \multirow[b]{3}{*}{ درجة المؤشر } & r & 9,0 & 14 & مدى تتاول الرسائل العلمية لقضايا تدريب وتتمية الموارد البشرية & 1 \\
\hline & - & - & - & تفعيلها. تناول الرسائل العلمية لموضوعات المشاركة الثعبية وسبل & r \\
\hline & - & - & - & ذداتياً. & r \\
\hline \multirow{3}{*}{ الكلية= درجة المؤشر } & 1 & $\varepsilon, \Lambda$ & 7 & مدى تتاول الرسـائل العلميـة لقضـايا التمويل الذاتي للمشروعات & $\varepsilon$ \\
\hline & - & - & - & تتمية الموارد البثرية. & 0 \\
\hline & - & - & - & مدى تتاول الرسائل العلمية لسبل دعم قدرات منظمات المجتمع & 7 \\
\hline
\end{tabular}

يتضـح مـن الجدول السـابق أن درجـة تتـاول الرسـائل العلميـة لقضـايا التتميـة البشـرية والتمكين والمشاركة الشعبية كأحد مؤشرات البعد الاجتماعي والبيئي للتمية المستدامة هي (1/) درجة بمنوسط حسابي (r) بنسبة (r, ع (\%) وبذللك تحدد مدى تعرض الرسائل العلمية لقضايا هذا البعد بتقدير كيفي (متوسط) وفق دليل التحليل، أما عن تتاول الرسائل العلمية لكل مؤثر فرعي داخل هذا المؤشر العام فقد اتضح أن درجة تتاول الرسائل العلمية لقضايا التدريب وتتمية الموارد البشرية قد جاء في الترتيب الأول بحصولها على (Y I) درجة بمتوسط حسابي (Y) بنسبة (9,0\%)، وبذلك تحدد تتاول الرسائل العلمية لهذا المؤشر بتقدير كيفي (أقل من المتوسط)، بينما

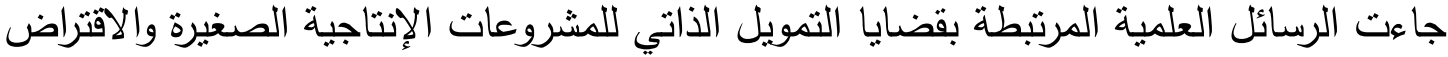
في الترتيب الثاني بحصولها على (7 درجات) وبمتوسط حسابي (1) وبنسبة مئويسة (^,ع٪) وبذلك تحدد مدى تعرض الرسائل العلمية لقضايا هذا المؤشر بتقدير كيفي (ضعيف) في حين لم تتعـرض أي مـن الرسـائل العلميـة خـلال الفترة المختارة لأي موضـوعات ذات صـلة بالمشـاركة 
الثعبية وسبل تفعيلها، وكذلك قضايا التمكين وإدارة المشروعات ذاتياً ودور مؤسسات المجتمع المدني والمؤسسات الحكومية لحصولهم على تقدير كيفي (ضعيف جداً) وفق دليل التحليل.

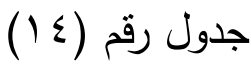
خاص بالمؤشر السادس المتعلق بـ مدى تتاول الرسائل العلمية لقضايا البيئة والمخاطر التي تهددها

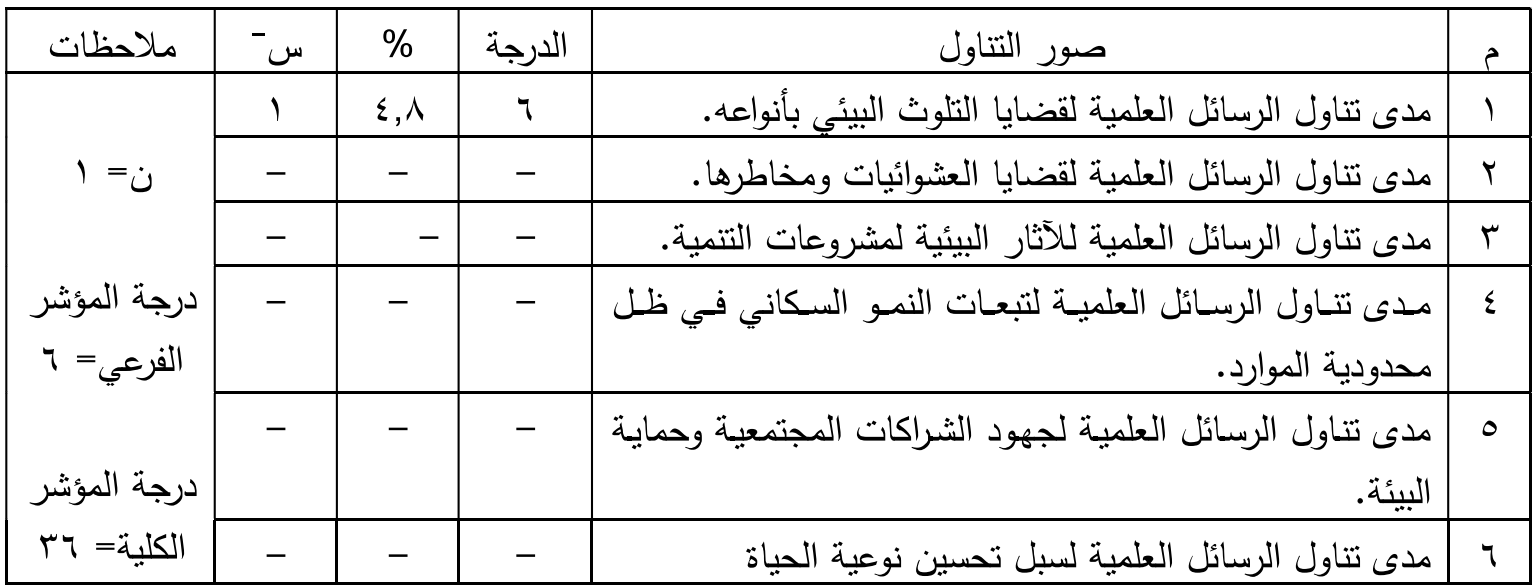

يتضح من الجدول السابق أن درجة تتاول الرسائل العلمية لقضايا البيئة والمخاطر التي تهددها كأحد مؤشرات البعد الاجتماعي والبيئي للتتمية المستدامة هي (7) بمتوسط حسابي (1) بنسبة (^,^₹\%) وبذلك تحدد مدى تعـرض الرسـائل العلميـة لقضـايا هذا المؤشر بتقدير كيفي (ضعيف) وفق دليل المحتوى، أما عن تتاول الرسائل العلمية لكل مؤشر فرعي داخل المؤشر الكلي، فنجد أن كلاً من القضايا المتعلقة بالتلوث البيئي بأنواعه والقضايا المتعلقة بسبل تحسين

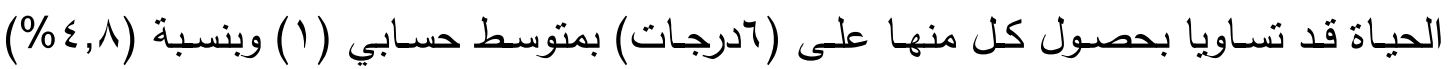
وبذللك تحدد تتاول هذا المؤشر بتقدير كيفي (ضعيف) وفق دليل المحتوى. كما نستتج كذلك من الجدول عدم تعرض الرسائل العلمية لقضايا العشوائيات ومخاطرها وقضايا البيئة وعلاقتها بالتتمية والنمو السكاني، والثراكات المجتمعية ودورها في حماية البيئة الأمر الذي يعني أن هناك موضوعات وقضايا متعلقة بالبعد الاجتماعي والبيئي تحتاج إلى مزيد من الاهتمام والبحث من قبل تخصصات المهنة، مع الإشـارة إلى أننا نتحدث عن فترة زمنية يجب أن يقترب فيها البحث العلمي وقضاياه لمعالجة مشكلات المجتمع المعاصرة وهو الأمر الذي يحتاج إلى مراجعة خطط وسياسـات البحث العلمي في تلك الكليات بما يخدم المجتمع ويعالج قضاياه. 


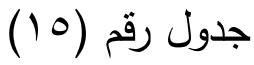

يوضح النتائج النهائية للتساؤل الفرعي الثاني المتعلق بمدى تتاول الرسائل العلمية للخدمة

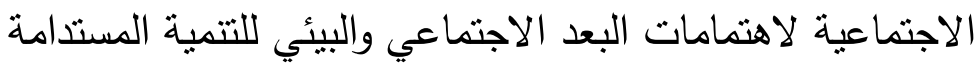

\begin{tabular}{|c|c|c|c|c|c|}
\hline الترتيب & 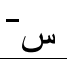 & $\%$ & 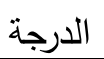 & صور التتاول & s \\
\hline r & 0 & $r \mathrm{r}, \Lambda$ & r & مدى تتاول الرسائل العلمية لقضايا التعليم & 1 \\
\hline$\varepsilon$ & 1 & $\varepsilon, \wedge$ & 7 & مدى تتاول الرسائل العلمية لقضايا الوعي الاجتماعي & r \\
\hline 1 & $1 \cdot$ & $\varepsilon \vee, 7$ & 7. & 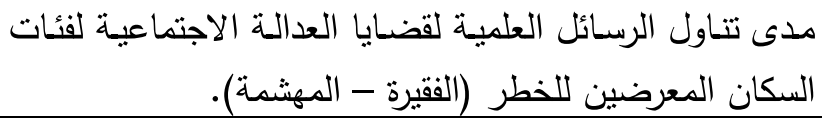 & r \\
\hline 0 & 1 & $\varepsilon, \wedge$ & 7 & مدى تتاول الرسائل العلمية لقضايا الرعاية الصحية. & $\varepsilon$ \\
\hline r & $r$ & $1 \varepsilon, r$ & 11 & والمشاركة الثـعبية. & 0 \\
\hline 7 & 1 & $\varepsilon, \wedge$ & 7 & 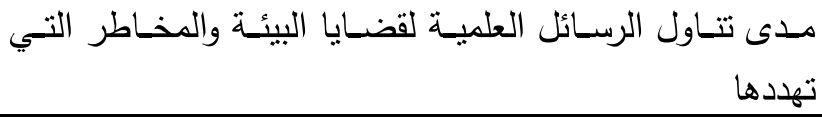 & 7 \\
\hline & YI & $\% 1 \ldots$ & $1 Y 7$ & المجموع & \\
\hline
\end{tabular}

يتضـح من الجدول السـابق والمتعلق بنتائج البعد الخاص بمدى تتاول الرسائل العلمية

للخدمـة الاجتماعيـة لاهتمامـات البعد الاجتمـاعي والبيئي للتتميـة المستـامة بحصـول المؤشـر

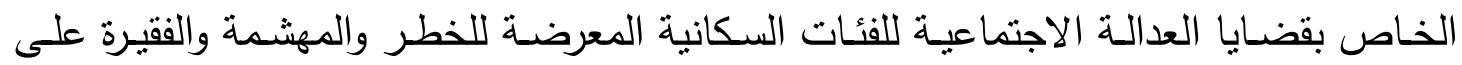

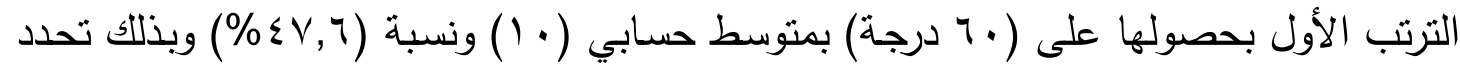
مدى تعرض هذا المؤشر لقضايا البعد الاجتماعي والبيئي بتقدير كيفي (متوسط) وفق دليل

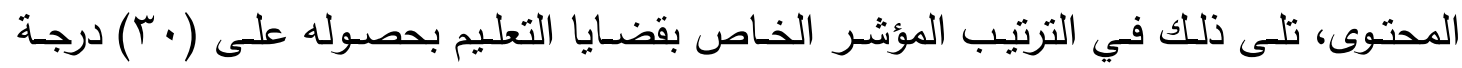

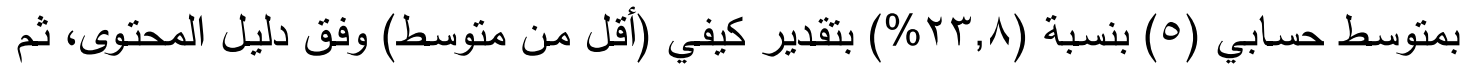

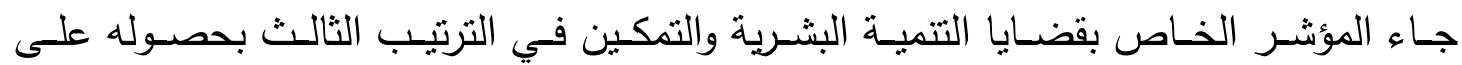

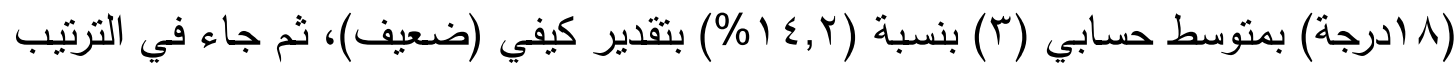

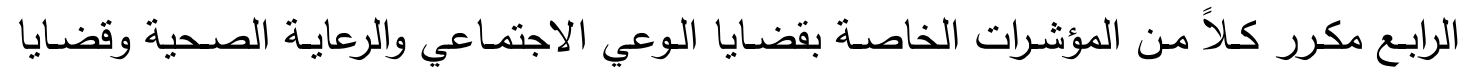
البيئة بحصولها على (آدرجات) بمتوسط حسابي (1) بنسبة (^,^ء\%) بتقدير كيفي (ضعيف). 
رسم بياني يوضح شكل واهتمامات الباحثين بقضايا البعد الاجتماعي البيئي للتتمية المستدامة من خلال الرسائل العلمية للخدمة الاجتماعية المتعلقة بنتائج التساؤل الثاني

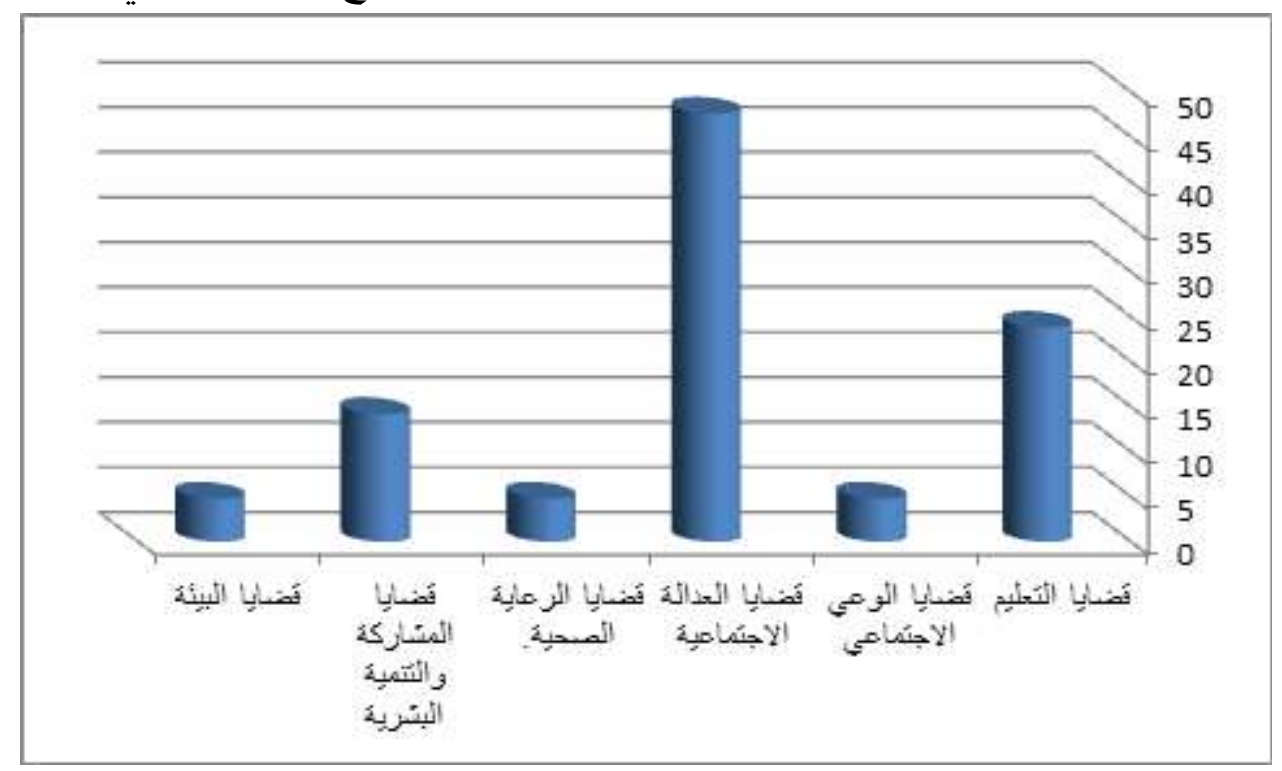

يوضح لنا الرسم البياني السابق ما يلي: الي

1- أن هناك تتوع وتطرق لكل القضـايا المرتبطة بالبعد الاجتماعي للتنمية المستدامة من قبل الباحثين ولكن ليس بالكفاية المرجوة.

r- أن هناك حالة من التباين في درجة الاهتمام لكل قضية من القضايا المطروحة. r- أن هذا التباين يعطي مؤشراً واضحاً لوجود خلل في خطط واستراتيجيات البحث العلمي وأن الباحثين لا يسيرون وفق نهج وخط فكرى وعلمي مخطط، والدليل على ذلك أن أعلى نسبة اهتمـام كانـت لقضـايا العدالـة الاجتماعيـة (للفئـات السـكانية الفقيـرة - المهشـمة المعرضـة

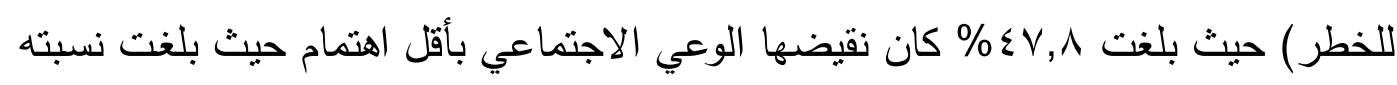
^, § \% والذي يفترض أن يسير جنباً إلى جنب معها إذا أردنا مشاركة فاعلة من المواطنين وتتميـة مستدامة لا خدمات ورعايـة اجتماعيـة مؤقتة، كمـا أن تلك النسبة لا تعطي دلالـة حقيقية على قيام الدولة بمسئولياتها تجاه قضايا الفقراء والفئات المهثمة، فتلك النسبة هي لجهود مؤسسات ومنظمات المجتمع المدني أنظر الجدول رقم (0). ع- كما أن ارتفاع مؤشر العدالة الاجتماعية بنـاء على الثكل السـابق هو مؤشر مضلل لأن

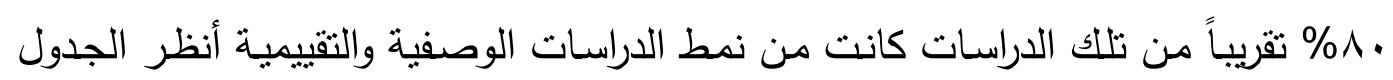


جدول رقم (17) - (17) - (19)

الخاص بنتائج التساؤل الفرعي الثالث المتعلق بـ مدى إسهامات الرسائل العلمية للخدمة

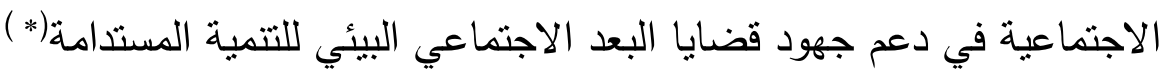

(وفق نتائج وتوصيات الرسائل العلمية هدف التحليل)

\begin{tabular}{|c|c|c|c|c|c|}
\hline \multirow[t]{2}{*}{ 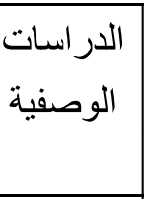 } & \multirow[t]{2}{*}{ التقر اسات } & \multicolumn{2}{|c|}{ من خلال در اسات عائد } & \multirow[t]{2}{*}{ صور إسهامات الرسائل العلمية في عملية التتمية المستدامة } & \multirow[t]{2}{*}{ ? } \\
\hline & & 5) & 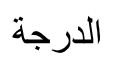 & & \\
\hline \multirow[t]{2}{*}{1} & 1 & & & 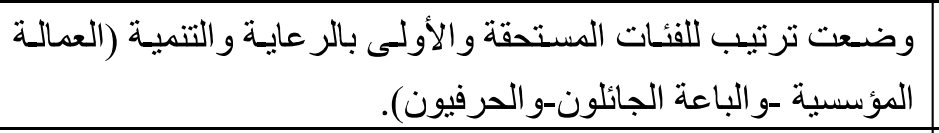 & 1 \\
\hline & 1 & & & أنشارت على فاعلية بر امج شبكات الأمان الاجتماعي في تحسين نو عية & r \\
\hline 1 & & & & 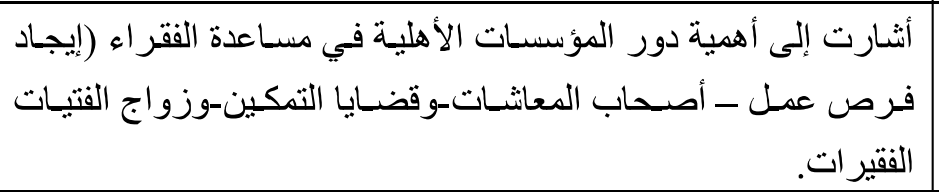 & r \\
\hline 1 & & & & 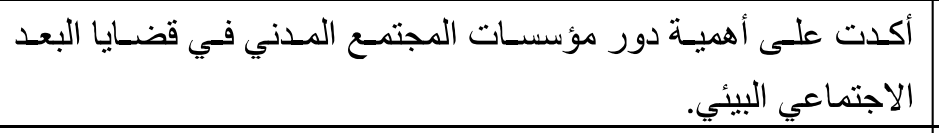 & $\varepsilon$ \\
\hline \multirow[t]{2}{*}{1} & 1 & & & أوصت بوضع أسس لبنـاء عمليات الثـر اكة بين الحكومـة ومؤسسـات & ○ \\
\hline & 1 & & & 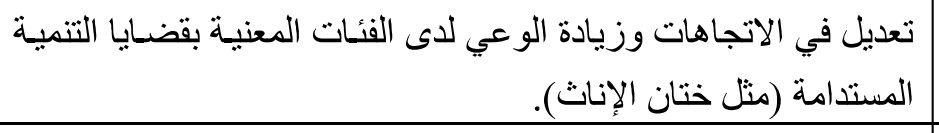 & 1 \\
\hline 1 & r & & 1 & 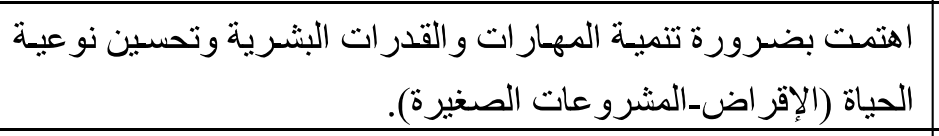 & 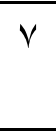 \\
\hline r & & & 1 & التنمية المستدامة المعوقات وجو انب القصور التي يجب التعامل معها في قضسايا & $\wedge$ \\
\hline \multirow[t]{2}{*}{ r } & 1 & & & دعمت المبادر ات و البر امج بالمعنية بقضايا التنمية المستدامة. & 9 \\
\hline & & & r & المقدم لهم الخدمة. النماذج المهنية المستخدمة في التأثير الإيجـابي على الفئات & 1 . \\
\hline$\% \leqslant \vee, 7$ & $\%$ & $\% 19,1$ & $\varepsilon$ & المجموع & \\
\hline
\end{tabular}

يتضح من الجدول السابق أن صور إسهامات الرسائل العلمية للخدمة الاجتماعية في

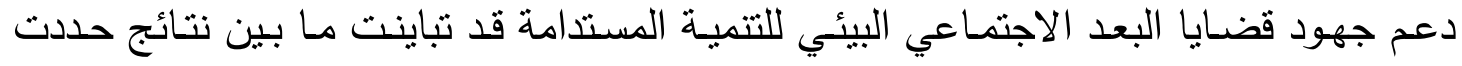

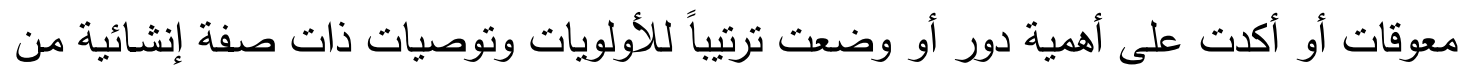

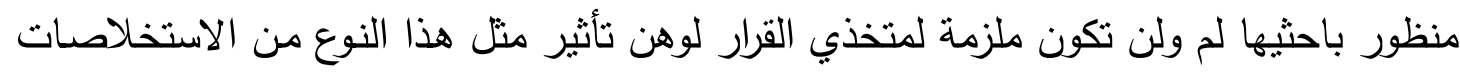

* بتصرف (تم الاستفادة من وضع مؤثرات هذا المحور من المعايير التي أثنار إليها أ.د/ جمال شحاتة في كتابه الممارسة العامة تصور حديث في الخدمة الاجتماعبة مرجع سبق ذكره. 
بحكم أنه لم يكن مؤثراً في بيئة الدراسة نفسها بحكم عدم ظهور أثر ملموس لتلك الاستخلاصات على المواطنين أنفسهم.

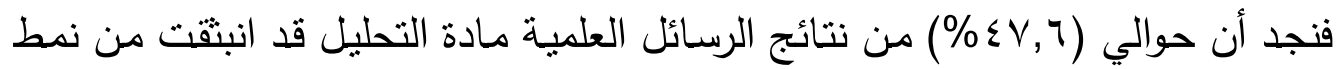

الدراسات الوصفية التحليلية. في حين أن (r, rr\%) من نتائج الرسائل العلمية مـادة التحليل قد انبتقت من نمط الدراسات التقييمية.

بينما بلغت نسبة إسهام الرسائل العلمية مادة التحليل في تلك النتائج والتي يمكن القول

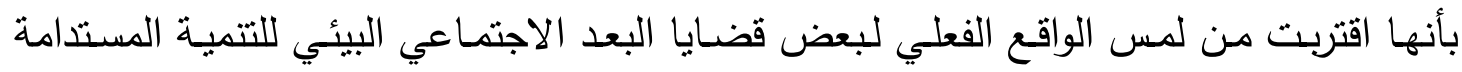

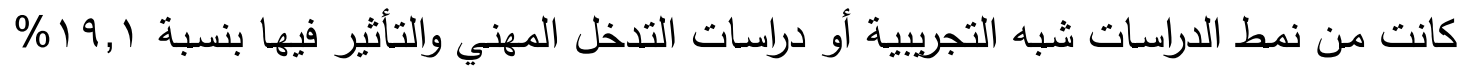

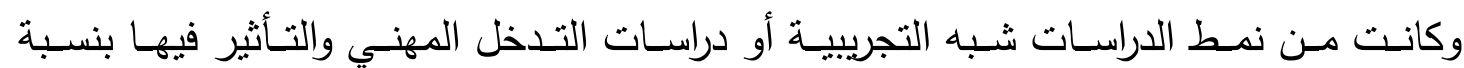

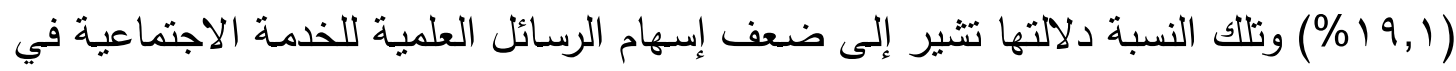
قضايا البعد الاجتماعي البيئي، واستتد الباحث للخروج بتلك النتيجة هو أنه حتى رسائل التدخل تلأك كان إسهامها في:

- - ملاحية بعض النماذج المهنية في بعض قضايا البعد الاجتماعي البيئي للتمية المستدامة. - - تعديل اتجاهات فئات وعينة الدراسة.

- - التأكيد على أهمية استخدام برامج تدريبية لتتمية القدرات البشرية لعينة الدراسة.

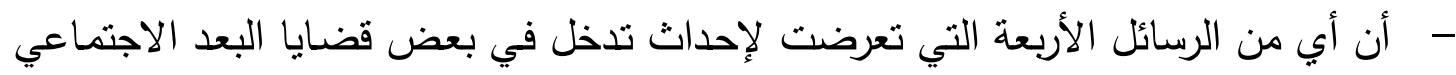

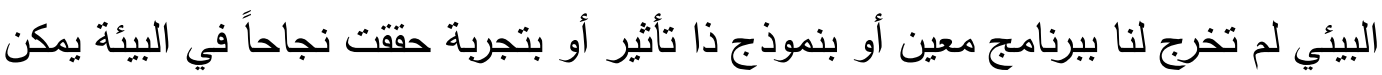

رسم بياني يوضح إسهامات الرسائل العلمية للخدمة الاجتماعية في دعم الجهود المبذولة في

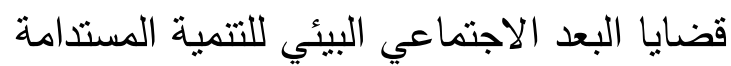

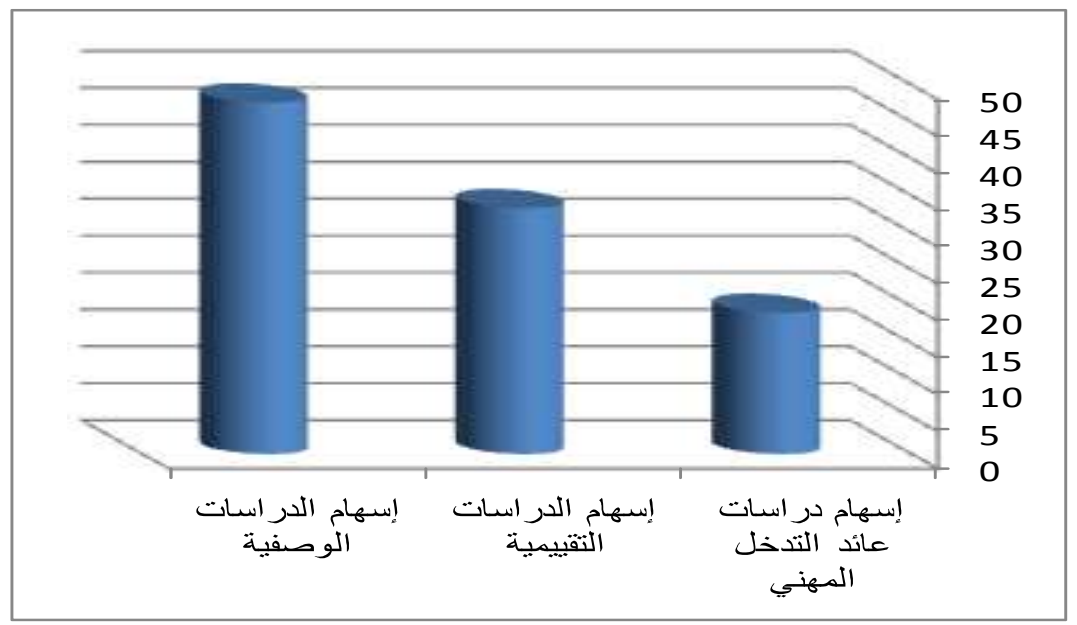


يتضح من الرسم البياني السابق ما يلي:

1- أن هناك قصور واضح في نمط دراسات التدخل المهني حيث جاءت في الترتيب الثالث على عكس المتوقع من أن يكون لهذا النمط من الدراسات النصيب الأكبر بحكم كونها تتعامل مع قضايا تحتاج إلى أن يشعر بها فئات المجتمع المتأثرين بقضايا البعد الاجتماعي البيئي للتنمية المستدامة. r- تركيز البحـث العلدي على نمط الدراسـات الوصفية التي تعتمــ على التحليل والتفسير

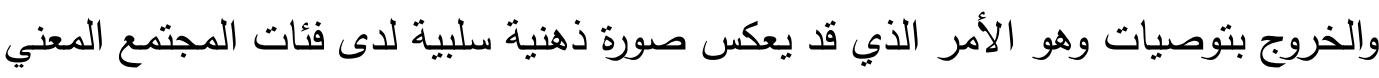

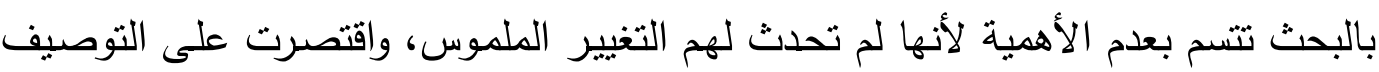
والتحليل فقط.

النتائج العامة للدراسة:

أولاً: بالنسبـة للنتائج المتعلقة بالتسـاؤل الفرعي الأول المتعلق بتوصيف الرسـائل العلميـة

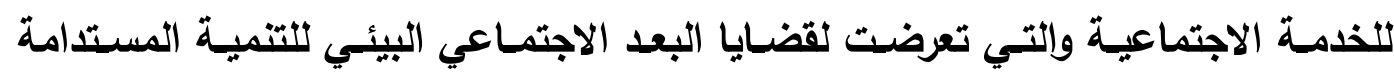

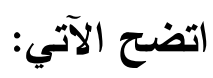

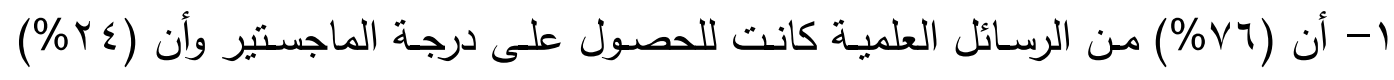
كانت للحصول على درجة الدكتوراه. r- أن هناك قصور واضح في التركيز على نمط الدراسات التي يمكن أن يكون لها إسهام

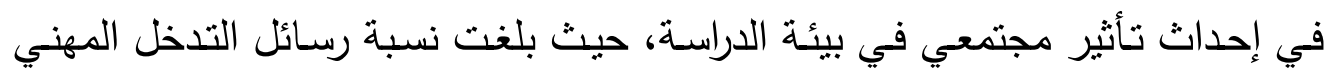
$.(\%) 9,1)$

r- غالبية القضايا التي تعرضت لها الرسائل العلمية تركزت في المناطق الحضرية الفقيرة وذلك بنسبة (1) ( ع - أنه بالرغم من التتوع الكبير في الفئات التي تتاولتها الرسائل العلمية وعنيت بها إلا أن هذا التتوع لم يكن ذا ميزة لأنه شتت الجهود ولم يحدث تأثيراً في فئة بعينها لقلة الرسائل التي تعرضت لكل فئة.

ه- أن نركيز الرسائل العلمية حول التأصيل النظري انصب بصورة مـا على الجمعيات

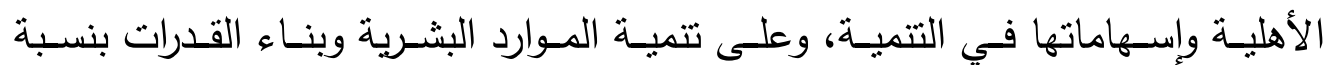

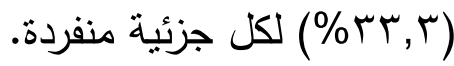


7- أن أكثر المداخل والأسس النظرية المهنية تصب على التخطيط الاجتماعي، وهو أمر منطقي لأن غالبية الرسائل كانت ذات صبغة وصفية تحليلية وتقويمية، وليست من نمط دراسات عائد التذخل المهني التي بستخدم فيها اختبار نموذج أوبرنامج تدخل مهني. ثانياً: بالنسبة للنتائج المتعلقة بالتسـاؤل الثاني الفرعي المتعلق بـ تحديد مدى تتاول الرسـائل العلمية للذدمة الاجتماعية لاهتمامات قضايا البعد الاجتماعي البيئي للتتمية المستدامة جاء

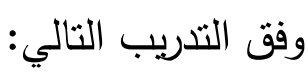
1- جـاء فـي الترتيـب الأول اهتمـام الرسـائل العلميـة بقضـايا العدالـة الاجتماعيـة للفئات

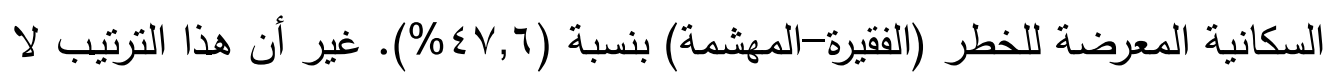

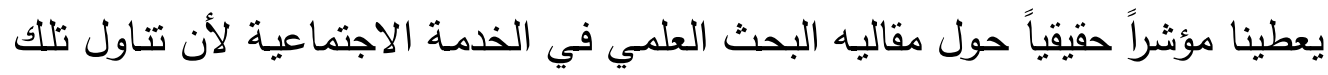
البحوث اتسم بتقليدية التتاول واقتصر على الوصف أكثر من التدخل الحقيقي لإحداث تغييراً في نمط حياة تلك الفئات. r- وفي الترتيب الثاني جاء اهتمام الرسائل العلمية بقضايا التعليم (تعليم الفتيات (مدارس

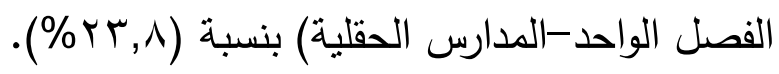
r- بينما جاءت قضايا التمكين والتتمية البشرية في الترتيب الثالث بنسبة (r,ع (1\%).

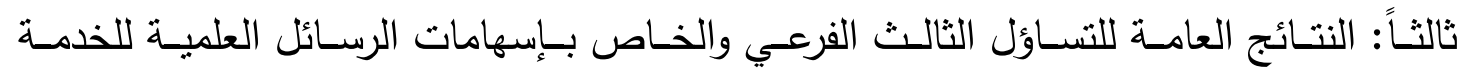
الاجتماعية في دعم جهود قضايا البعد الاجتماعي البيئي للتنمية المستدامة: 1- فقد خلصت إلى اتجاه صور الإسهام كانت ما بين التوصيف لنتائج وتوصيات والتأكيد

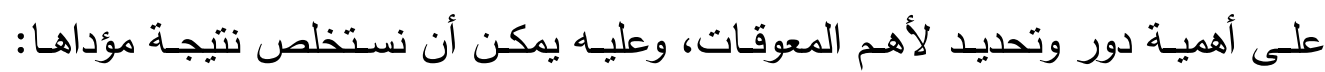

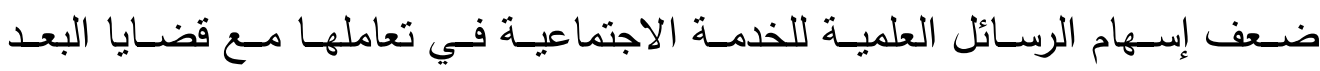
الاجتماعي للتنمية المستدامة نظراً لتقليدية التتاول لها. ז- تمحور الرسائل التي اتجهت إلى نمط الدراسات شبه التجريبية حول تعديل اتجاهات أو زيادة وعي. r- عدم خروج أي من الرسائل ببرامج أو مبادرات ثبتت فاعليتها أو تجارب يمكن تعميمها

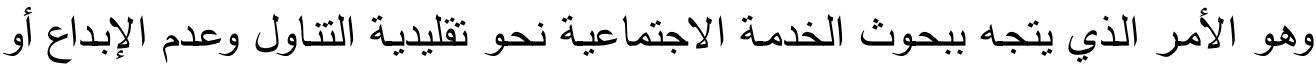

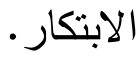


نتائج التشاؤل الرئيسي الثالث المتعلق بوضـع آليات لتفعيل الرسـائل العلميـة للخدمة الاجتماعية في قضايا البعد الاجتماعي للتنمية المستدامة. اعتمدت منطلقات وضع آليات التفعيل للرسائل العلمية للخدمة الاجتماعية عند التتاول

$$
\begin{aligned}
& \text { النوعي لقضايا البعد الاجتماعي البيئي للتنمية المستدامة على الآتي: } \\
& \text { ا- نتائج الدراسة العلمية الحالية والتي كان أبرزها: }
\end{aligned}
$$

أ- أن هنالك تقليدية في تتاول الدراسات العلمية للقضايا المرتبطة بالبعد الاجتماعي والبيئي للتمية المستدامة.

ب- أن نتائج تلك الدراسات غلب عليها الطابع التنظيري أكثر منه الممارس التي يمكن أن تحدث فارقاً في الفئات الأولى بالرعاية والتتمية.

ج-ترتب على ذلك غياب مشـاركة المـواطنين في تغيير نمط واقعهم بحكم نمطيـة أنواع الدراسات المستخدمة.

د-عدم الخروج بأي برامج أو مبادرات ناجحة تعزز من وعي المواطنين وتتمي قدراتهم بما يمكنهم من تغيير أسلوب حياتهم للأفضل. ץ- العمل بعيداً عن التأصيل النظري للجانب الاجتماعي في التتمية المستدامة والذي ينطلق من

$$
\text { مفهومات وركائز متمثلة في: (سليمان، وآخرون، ه . . ب) }
$$

أ- أن التتمية المستدامة تعني الاستمرارية والتواصل في الوفاء باحتياجـات الحاضـر دون الإخلال بقدرة الأجيال القادمة على الوفاء باحتياجاتها (أي العمل على استخدام الموارد (المتجددة).

ب-تمكين النـاس بـدلاً مـن تهميشهر (فهناك ارتبط وثيق بين التتميـة المستدامة، والتتميـة البشرية، والعدالة الاجتماعية، والشراكات المجتمعية، والتمكين). ج-إتاحة الفرص للمشاركة لكافة فئات المجتمع مع تعظيم الاهتمام بدور المجتمع المدني ومنظماته ودوره في المشاركة الفعالة في عملية التتمية المستدامة. د - أهمية تبني مدخل التخطيط بالمشاركة.

هـ-الواقعية والمرونة في خطط التتمية بما يضمن استمراريتها. و -العمل وفق آليات التمية المستدامة والتي من بينها الآلية الثانية المتعلقة بتسخير العلم لأغراض التتمية المستدامة والثالثة المتعلقة تعزيز التعليم والوعي العام والتدريب. 


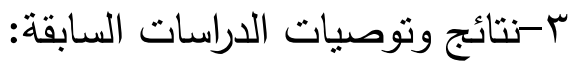

وفقاً للمعطيات السـابقة يمكن بلـورة آليات تفعيـل الرسـائل العلميـة للخدمة الاجتماعيـة لتصبح أكثر فعالية وتتسم تدخلاتها المهنية بالإبداع في الآراء والابتكار في التجارب والبرامج المتعلقة بقضايا البعد الاجتماعي البيئي للتمية المستدامة وذلك من خلال وضع رؤية تكاملية لمنظومة العمل التمـوي تستند فلسفتها على إستراتيجية واضحة اخذه فى الاعتبار أن مجتمع المعرفة المعاصر لم يعد منتجاً فقط للمعارف والأفكار بل تعاظم دوره ليترجم تلك المعارف إلى إلى تجارب ونماذج وابتكارات واختراعات نجم عنها تقدم تكنولوجي في شتى المجالات وهكذا يجب أن تسـتـد فلسـفة ورؤيسة واسـتراتيجيات البحث العلمسي للخدمـة الاجتماعيـة أن تكون مؤسسـاتها البحثيـة منتجـة تسـهم في إحداث تتميـة مسـدامة قائمسة على تجارب ومبـادرات وبـرامج تصـلح كنماذج يحتذى بها محلياً وإقليمياً وقبل كل ذلك يشعر المواطن بأثرها وتحسن من مستوى معيشته ويمكن أن يتحقق ذلك من خلال الروئية ثلاثية الأبعاد الممثلة في الآتي:

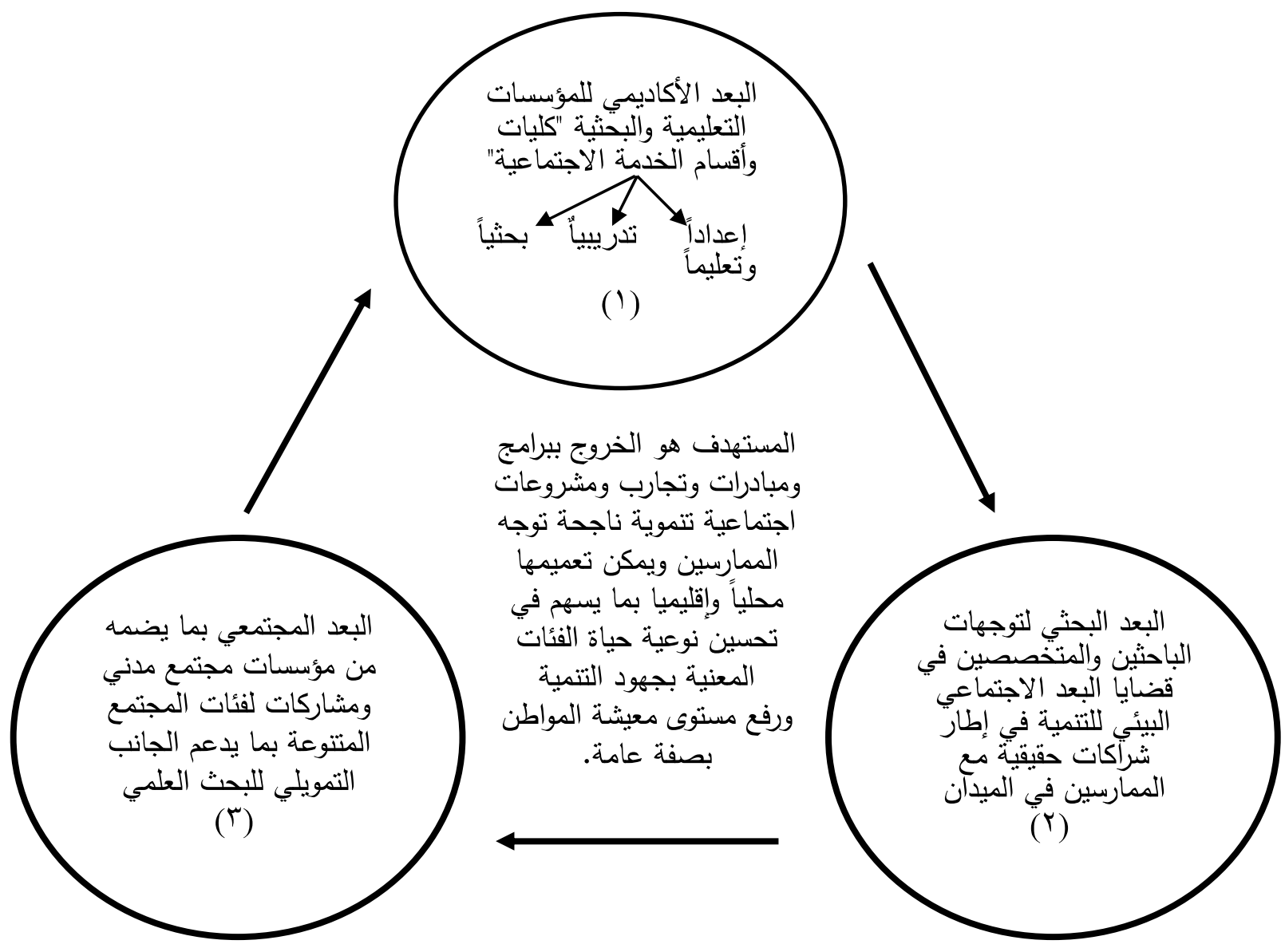


أولاًَ-فيما يتعلق بالبعد الأكاديمي للمؤسسات التعليمية والبحثية "كليات وأقسام الخدمة الاجتماعية" يجب أن يحدد رؤيته وفق مسارثلاثى الأبعاد "ممثلا في مواكبة نظم تعليم الخدمة الاجتماعية للفكر المعرفي المعاصـر -الاهتمـام ببحـوث النموذجـة-التـريب وتتميـة المـوارد البثـرية" وهذا يتطلب ضرورة.

ا- إعـادة النظر في لائحسة الدراسـات العليـا بكليـات الخدمـة الاجتماعيـة وأقسـامها وفـق واقـع المجتمع المعاصر وقضاياه ذات البعد الاجتماعي بحيث يراعى فيها: أ- وضـع إستراتيجية متكاملة للبحث العلمي ذات رؤية واضحة ومحددة تخدم قضايا البعد الاجتماعي البيئي للتتمية المستدامة. ب-إعداد دراسـات علميـة يكون هدفها تحديد قضـايا المجتمع المرتبطة بالبعد الاجتمـاعي وبلـورة نتائجها مـن خـلال مقترحسات بموضـوعات متتوعـة شـاملة لكـل فئـات السـكان المستهدفين في عملية التتمية المستدامة يختار الباحثين من بينها ما يمكن أن يكون فكرة رسالته العلمية، وذلك يحقق أهداف رسالة الكلية من التتاول الحقيق المطلوب لقضايا المجتمع التتموية، وخدمة البيئة الجغرافية للمجتمع المحيط بها. ج-إعادة النظر في مراكز البحوث والدراسـات العلمية بالكليات سواء من حيث أهدافهاوخططها المسـتقبلية ودورهـا المجتمعـي لتصـبح بيـوت خبـرة علميـة، ومركز إثـعاع متخصص يخدم بيئة المجتمع المحلي ومؤسساتها الاجتماعية الحكومية منها والأهلية. r-فتح آفاق التعاون والثراكات العلمية بين مراكز البحوث على المستوى الأكاديمي بين كليات الجامعة الواحدة، ثم الانتقال إلى إقامة تكتلات علمية بحثية بين الجامعات لتكون نواة لتتفيذ مشروعات قومية مرتبطة بقضايا البعد الاجتماعي البيئي للتتمية المستدامة، وهو الأمر الذي يحقق: أ-التمكن من خـلال وجود رؤيسة واضحة المعالم نستطيع وفقاً لها التعامل الأمثل مهع مجتمع المعرفة المتتامي وفق تكتل معرفي له صيغة وهوية وطنية وقدرات تتافسية. ب-توحيد الهدف حول المشروعات البحثية الأكثر ارتباطاً بالمواطنين. ج-إثراء الأفكار والمفاهيم البحثية الأكثر ملائمة وفق بيئات المجتمع المحلية. د-تبادل الخبرات وتتوعها بما يفرز أفكاراً وإرهاصات تتسم بالابتكار والمواطنة. 
هـ-تتسيق الجهود وعدم تشتتها بما يفرز مشروعات وتجارب وبرامج ناجحة تعالج قضايا البعد الاجتماعي البيئي للتنمية المستدامة.

ثانياً: فيما يتعلق بالبعد البحثي لتوجهات الباحثين والمتخصصين في قضايا البعد الاجتماعي البيئي للتمية، وذلك وفق منظومة واضحة من الثراكات مع الممارسين المهنيين في الميدان وهو

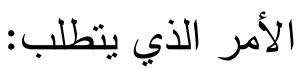

ا- إعادة النظر في توجهات باحثي ومخططي من ناحية وممارسي الجهود التتموية من ناحية أخرى:

أ- فيما يتعلق بباحثي الماجستير والدكتوراه، يجب إعدادهم وفق منظومـة الاحتياج المجتمعي ليصبح كل منهم متخصص وذو خبرة في جانب معين يمنل خطاً فكرياً محدداً. - تتمية وتطوير مهارات الباحثين من خلال نهج علمي يساعده على النشر العلمي خلال مرحلة الماجستير والدكتوراه مرتبطة بموضوع بحثه ليتبادل فيها خبراته مع الاخرين ويطرح رؤيته لكيفيف معالجة القضية البحثية التى يدرسـها وتكون فى الوقت ذاتة من مسوغات الحصول على الدرجة العلمية للمرحلة التي يدرس فيها. - توجيه الباحثين نحو البحوث التطبيقية، ذو الطابع الذي يتسم بالتخخلات المهنية أكثر منها استطلاعية، أو وصفية، بمـا قد يفرز للمجتمع بـرامج، أو تجـارب مهنيـة ناجحسة يمكن تعميمها، والبعد عن الاستغراق في تحليل الوضع القائم. ب-فيما يتعلق بمخططي وممارسي الجهود التموية الميدانيين: • - - يراعى تمكينهم من التأثير الفعال في النسق المؤسسي والبيئة المحيطة بها، وهو الأمر الذي يتطلب تتمية مهاراتهم البحثية والعلمية باعتبارهم الأكثر قرباً من المواطنين والأكثر تأثيراً في حشد واستثمار طاقات المواطنين كطرف أصيل في تحقيق عناصر التتمية المستدامة البشرية والبيئية ولن يتمكن مخططي وممارسي الجهود التتمية من ذلك إلا من خلال: (التعليم المستمر، التدريب الفعال، تبادل الخبرات) ثالثاً: فيمـا يتعلـق بالبعـد المجتمعسي والثــراكات المؤسسـية بـين مؤسسـات المجتمسع المـدني والمؤسسات الحكوميتفأن الامر يحتاج الى ضرورة. 1- تحديد رؤية واضحة حول أسلوب التعاون وأشكاله بين مؤسسات المجتمع المدني والقادرة على دعم وتمويل البحوث العلمية والمؤسسات الأكاديمية البحثية. 
r- رصد التحديات التي تؤثر على تحقيق شراكات فاعلة بين المؤسسات الاجتماعية الأهلية والحكومية.

r- وضع برامج زمنية لخطط التعاون وعمليات التتفيذ بما يسمح بأجراء التقييم المستمر لجهود تللك المؤسسات وتحديد سبل تطوير أدائها.

ع- إعطاء مزيد من الاهتمام لمشاركات المواطنين كطرف فاعل في إحداث التتمية والمحافظة على ما تحقق منها وذلك بتتويع أساليب توعيتهم وتحسين قدراتهم ومهاراتهم التشاركية في عمليـة التتميـة وفـق رؤيسة تـدعم لـديهم قيم العدالـة الاجتماعيـة والاسـتيعاب لا الإقصـاء

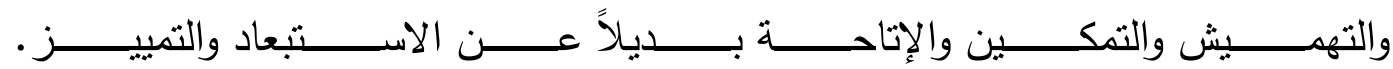


ا ـ إدريس أحمد عبد الله: مشكلات البحوث العلمية التربوية كما يراها طلبة الدراسات العليا،

$$
\text { مرجع سبق ذكره. }
$$

r. البار ، حسن بن عبد القادر حسن: الثقافة الفكرية في التتمية المستدامة، طا، السعودية، .$r \ldots$

r. بارود، نعيم سليمان: منطلبات التتمية المستدامة والمتكاملة من المؤشرات الإحصائية، بحث

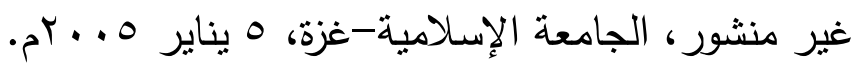
ع. جمال الدهثان: العلاقة الإستراتيجية بين البحث العلمي الجامعي والصناعة "الواقع والآفاق المستقلية"، ورقة عمل في الندوة السابعة "التخطيط الاستراتيجي للتعليم العالي، كلية التربية،

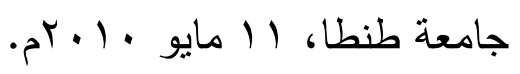

•. جمال الدين، محمد: دراسة للتعرف على مدى فاعلية البحوث والدراسات العلية في تطور

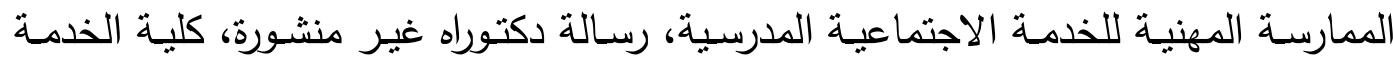
الاجتماعية، جامعة القاهرة، 990 (م.

7. حبيب، جمال شحاتة: الممارسة العامة من منظور حديث في الخدمة الاجتماعية، المكتب

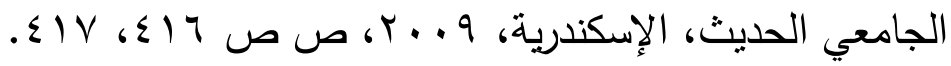

V. الخصاونة، محمد: أهمية توجيه البحث العلمي لتحقيق التتمية المستدامة، عمان، ب ا • Tم. ^. الدوش، علي عبده: علاقة البحث العلمي بالتتمية من وجهة نظر أعضاء هيئة التدريس بجامعة عدن، رسالة ماجستير غير منشورة، المركز الوطني للمعلومات، رئاسة الجمهورية،

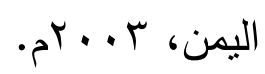

9. ربيع، رفعت: البحث العلمي وتحقيق التتمية المستدامة، مجلة التنمية الإدارية، العدد (·ـ ( )،

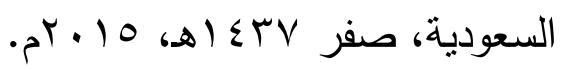

• . . طعمية، رشدي: تحليل المحتوى في العلوم الإنسانية، دار الفكر العربي، القاهرة، 19AV. 11. عبد التواب، ناصر عويس: الاحتياجات التدريبية لتتمية مهارات الأداء المهني للأخصائيين

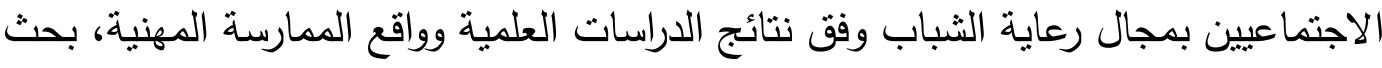

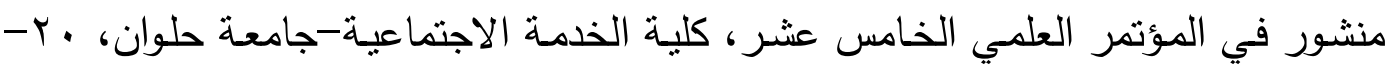

$$
\cdot 5 r+r / 4 / 2
$$


با . عبـد التـواب، ناصـر عـويس: نحـو برنـامج مقتـرح لتطـوير الإعـداد المهنـي للأخصـائيين الاجتماعيين في مجال رعاية الثباب، رسالة دكتوراه غير منشورة، كلية الخدمة الاجتماعية،

جامعة القاهرة، 999 (م.

با . عبد الجواد، أحمد عبد الوهاب: التربية البيئية (سلسلة دار المعارف البيئية)، القاهرة، الدار

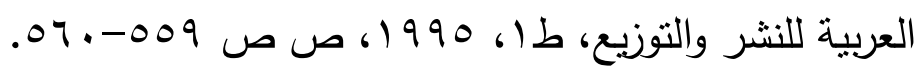

ع ا. ـ عبد العال، عبد الحليم رضـا: تتظيم المجتمع التطوير والتطبيق، القاهرة، المطبعة التجارية

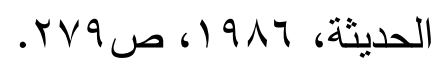

1 . . عبد المقصود، تقويم إسـهامات البحوث والدراسـات العلمية في تدعيم الممارسـة المهنية في مجال تتمية المجتمع، رسالة دكتوراه غير منشورة، كلية الخدمة الاجتماعية، جامعة القاهرة، . 1990

7 ا . عبدا لله، إدريس أحمد: مشكلات البحوث العلمية التربوية كما يراها طلبة الدراسات العليا،

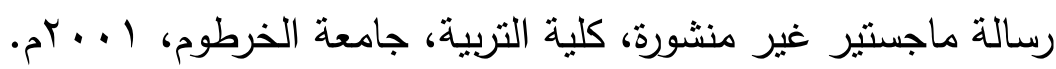
V ا ـ ألغامـدي، عبـد الله جمعـان: التتميـة المسـدامة (بـين الحـق في اسـتغلال المـوارد الطبيعيـة والمسئولة عن حميـة البيئة، جامعـة الملك سـود، قسـم العلوم الإنسـانية، المملكة العربيـة

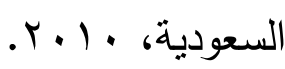

1 ا. القحطاني، منصور : الإنفاق على البحث العلمي الجامعي، الواقع والمأمول، ورقة عمل مقدم

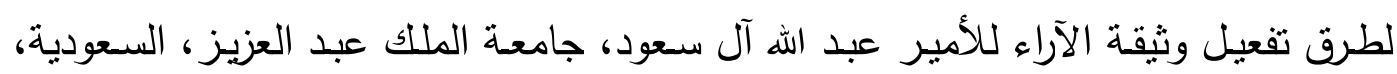
$\cdot{ }^{2}+0$

9 1. القصساص، مهدي محمد: البحث العلمي وتطلعـات البـاحثين، بحث منشـور في المـؤتمر

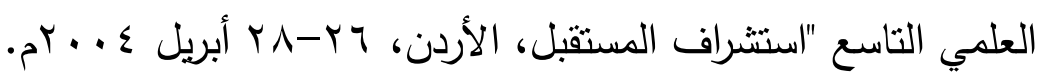
• r. كنسـاوي، محمود محمد عبد الله: توجيه البحث العلمي في الدراسـات العليا في الجامعات السعودية لتلبية متطلبات التتمية الاقتصادية والاجتماعية الواقع - توجهات مستقبلية، ندوة

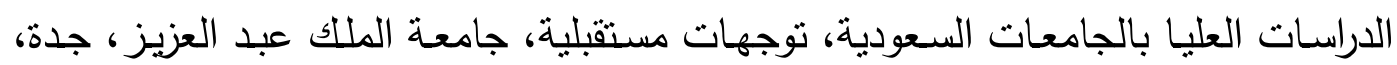

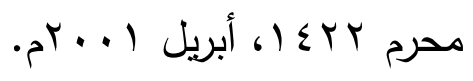

ا ب. اللحلح، أحمد أحمد عبد الله: ثفعيل العلاقة بين مؤسسات البحث العلمي وقطاعات الأعمال

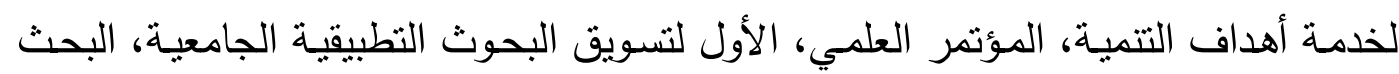

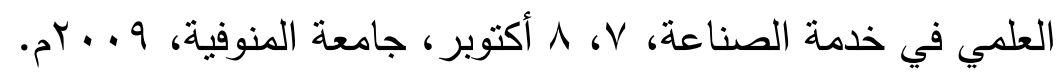

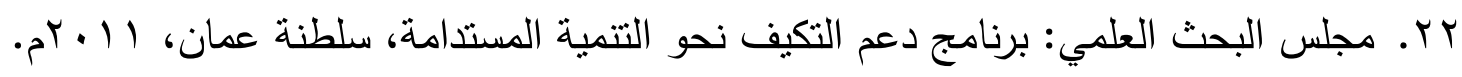


بr. محمد، أحمد الثيخ: اتجاهات البحث العلمي التربوي، رسالة ماجستير غير منشورة، كلية التربية، جامعة الخرطوم، 999 (م.

ع ז. محمد، علي محمد: علم الاجتماع والمنهج العلمي، سلسلة علم الاجتمـاع المعاصر ، دار

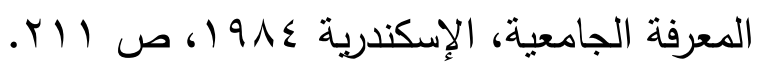

هr. المعهد الفيـرالي التقنـي، المركـز السويسـري لبحـوث الثـمال والجنـوب: زيـورخسويسـرا، .$r .1 T$

جr. المنتدى العربي للبحث العلمي والتتمية المستدامة: المنظمة العربية للتربية والثقافة والعلوم،

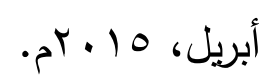

V.r. المؤتتمر الإســلامي للوزراء المكلفين بالبيئة في دول منظمـة المـؤتمر الإســامي: المملكة

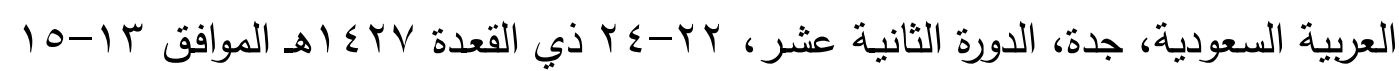

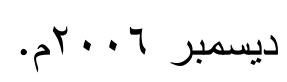

^ז. المؤتمر الإقليمي العربي حول التعليم العالي: نخو فضاء عربي للتعليم العالي: التحديات

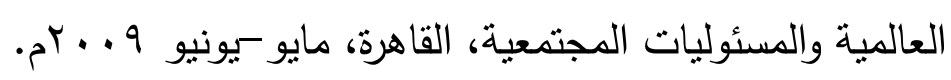

و ب. المؤتثر الدولي الثاني عشر للمؤسسات الوطنية لتعزيز حماية حقوق الإنسان (أهداف التنمية

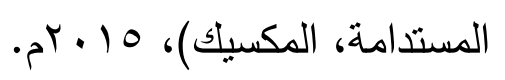

• ب. المؤتمر الدولي الرابع للبحث العلمي: البحث العلمي ركيزة التتميـة المستدامة في العصر الرقمي، مركز الأضواء الاجتماعي بالتعاون مع مركز البحوث الاستشارية الاجتماعية في

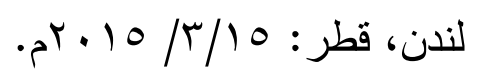

اس. المؤتمر العلمي حول دور الجمعيات الأهلية في التمية (البحث العلمي أساس التقدم، ج· م.

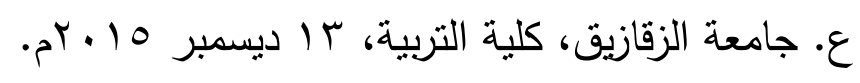

rr. الهادي، فوزي محمد: تقويم إسهامات الدارسات والبحوث في تدعيم الممارسة المهنية لطريقة خدمة الفرد في المجال الأسري، رسالة دكتوراه غير منشورة، كلية الخدمة الاجتماعية، جامعة ورية

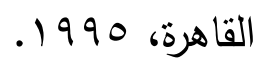

سب. وحدة الخطط وسياسـات النـوع بمعهد التخطيط القومي، النـوع والتخطيط والتنميـة، العـدد

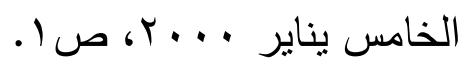
عـا. اليونسـكو: مؤسسـات التتميـة المسـتدامة وأطرافهـا الفاعلـة (مـن نتـائج مـؤتثر ريـو دى

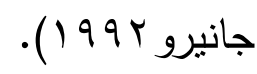

http:// www. Unisco.org/ most/sdarab/Fich4ahtm. 


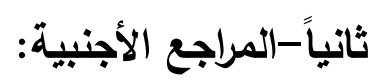

(1) Kevin Griffin: Sustainable Development، aver view، Departmental Office, The Earth institute office Academic and Research, in Collaboration with Columbia College, New yourk, 2014.

(2) Colin, Akhurst: Assessment of Performance in Professional Practice in Social Work Courses, Assessment in Higher Education, Vu n 1 pec 1978, pp. $46-59$.

(3) Mccart. Hess, Edward. j. Mullen: Practitioner- Researcher: Building knowledge from, in, and for practice op, cit.

(4)N. A. S. W: Standards for Social Work Professional Practice. U. S,: District of Columbia, 1990.

(5) Mccart. Hess, Edward. j. Mullen: Practitioner- Researcher: Building knowledge from, in, and for practice, 1995.

(6)The role of research in Social Work, University of New England, on line, masters of Social Work.

(7) Stanley L. Witkin: Towards a scientific social work journal of social work Research, volume 12, issue 3-4, 2008.

(8) Christa Fouche: Practice Research partnerships in Social Work, Chicago Distribution Center, 2015, P. 192. 